\title{
A combined methodology for the approximate estimation of the roots of the general sextic polynomial equation
}

Giorgos P. Kouropoulos ( $\nabla$ eetmecheng@gmail.com )

Technological Educational Institute of Athens https://orcid.org/0000-0003-2033-0034

\section{Method Article}

Keywords: sextic polynomial, general sextic, hexic polynomial, radical solutions, estimation of roots, approximate estimation, Galois theory, regression analysis, statistics

Posted Date: September 8th, 2021

DOI: https://doi.org/10.21203/rs.3.rs-882192/v2

License: (9) This work is licensed under a Creative Commons Attribution 4.0 International License.

Read Full License 


\title{
A combined methodology for the approximate estimation of the roots of the general sextic polynomial equation
}

\author{
Giorgos P. Kouropoulos \\ BSc in Energy Technology, Technological Educational Institute of Athens \\ E-mail: etmecheng@gmail.com \\ ORCID id: 0000-0003-2033-0034
}

\begin{abstract}
In this article we present the methodology, according to which it is possible to derive approximate solutions for the roots of the general sextic polynomial equation as well as some other forms of sextic polynomial equations that normally cannot be solved by radicals; the approximate roots can be expressed in terms of polynomial coefficients. This methodology is a combination of two methods. The first part of the procedure pertains to the reduction of a general sextic equation $\mathrm{H}(\mathrm{x})$ to a depressed equation $\mathrm{G}(\mathrm{y})$, followed by the determination of solutions by radicals of $\mathrm{G}(\mathrm{y})$ which does not include a quintic term, provided that the fixed term of the equation depends on its other coefficients. The second method is a continuation of the first and pertains to the numerical correlation of the roots and the fixed term of a given sextic polynomial $\mathrm{P}(\mathrm{x})$ with the radicals and the fixed term of the sextic polynomial $\mathrm{Q}(\mathrm{x})$, where the two polynomials $\mathrm{P}(\mathrm{x})$ and $\mathrm{Q}(\mathrm{x})$ have the same coefficients except for the fixed term which might be different. From the application of the methodology presented above, the following formulation is derived; For any given general sextic polynomial equation $P$ with coefficients within the interval $[\mathrm{a}, \mathrm{b}]$, a defined polynomial equation $\mathrm{Q}$ corresponds which has equal coefficients to $\mathrm{P}$ except for its fixed term which might be different and dependent on the other coefficients so that $\mathrm{Q}$ has radical solutions. If we assume a pair of equations $\mathrm{P}, \mathrm{Q}$ with coefficients within a predetermined interval $[\mathrm{a}, \mathrm{b}]$, the numerical correlation through regression analysis of the radicals of $\mathrm{Q}$, the roots of $\mathrm{P}$ and the fixed terms of $\mathrm{P}, \mathrm{Q}$, leads to the derivation of a mathematical model for the approximate estimation of the roots of sextic equations whose coefficients belong to the interval $[a, b]$.
\end{abstract}

Keywords: sextic polynomial, general sextic, hexic polynomial, radical solutions, estimation of roots, approximate estimation, Galois theory, regression analysis, statistics

\section{Appendix}

$H(x): \quad$ General sextic polynomial equation with coefficients $\alpha_{1} \ldots \alpha_{6}$.

$\mathrm{G}(\mathrm{y})$ : Depressed sextic equation, derived by from the reduction of $\mathrm{H}(\mathrm{x})$, with coefficients $\mathrm{p}, \mathrm{q}, \mathrm{r}, \mathrm{s}, \mathrm{t}$.

$\mathrm{P}(\mathrm{x}): \quad$ Given general sextic polynomial equation with coefficients $\alpha_{1} \ldots \alpha_{6}$ within the interval $[a, b]$. The interval $[a, b]$ is determined by the mathematical model that arises for the determination of the approximate solutions of $\mathrm{P}(\mathrm{x})$.

$\mathrm{Q}(\mathrm{x})$ : $\quad$ Dependent Sextic polynomial equation with coefficients $\mathrm{p}, \mathrm{q}, \mathrm{r}$, s, equal to the respective coefficients of $P(x)$ kal fixed term $t^{\prime}$ so that $t^{\prime}=f(p, q, r, s)$.

$\alpha_{1} \ldots \alpha_{6}$ : Coefficients of general sextic polynomial equation $\mathrm{H}(\mathrm{x})$ or given equation $\mathrm{P}(\mathrm{x})$.

p...t, $t^{\prime}$ : Coefficients of transformed polynomial equation $\mathrm{G}(\mathrm{y})$ or dependent polynomial equation $\mathrm{Q}(\mathrm{x})$.

$t^{\prime}$ : $\quad$ Fixed term of $Q(x)$ during the formation of the mathematical model for roots estimation, so that $\mathrm{t}^{\prime}=\mathrm{f}(\mathrm{p}, \mathrm{q}, \mathrm{r}, \mathrm{s})$. 


\begin{tabular}{|c|c|}
\hline$\Delta_{1}, \Delta_{2}:$ & Independent discriminants of $\mathrm{G}(\mathrm{y})$ or $\mathrm{Q}(\mathrm{x})$ \\
\hline$\Delta_{3}, \Delta_{4}:$ & Dependent discriminants of $\mathrm{G}(\mathrm{y})$ or $\mathrm{Q}(\mathrm{x})$ so that $\left\{\Delta_{3}, \Delta_{4}\right\}=\mathrm{f}\left(\Delta_{1}, \Delta_{2}\right)$ \\
\hline$\rho / \rho^{\prime}:$ & $\begin{array}{l}\text { Ratio between the roots of the given general sextic polynomial equation } \mathrm{P}(\mathrm{x}) \\
\text { and the dependent sextic polynomial equation } \mathrm{Q}(\mathrm{x}) \text { in the mathematical model. }\end{array}$ \\
\hline $\mathrm{t} / \mathrm{t}^{\prime}:$ & $\begin{array}{l}\text { Ratio between the fixed terms of the given general sextic polynomial equation } \\
\mathrm{P}(\mathrm{x}) \text { and the dependent sextic polynomial equation } \mathrm{Q}(\mathrm{x}) \text { in the mathematical } \\
\text { model. }\end{array}$ \\
\hline$f\left(t / t^{\prime}\right):$ & Numerical correlation between ratios $\rho$ / $\rho^{\prime}$ and $\mathrm{t} / \mathrm{t}^{\prime}$ using regression analysis. \\
\hline $\operatorname{Re}(\rho)$ & Real part of the root for the given polynomial equation $\mathrm{P}(\mathrm{x})$. \\
\hline $\operatorname{Im}(\rho)$ : & Imaginary part of the root for the given polynomial equation $\mathrm{P}(\mathrm{x})$. \\
\hline $\operatorname{Re}\left(\rho^{\prime}\right)$ : & Real part of the root for the dependent sextic equation $Q(x)$ \\
\hline $\operatorname{Im}\left(\rho^{\prime}\right):$ & Imaginary part of the root for the dependent sextic equation $\mathrm{Q}(\mathrm{x})$ \\
\hline$f_{\mathrm{Re}}:$ & $\begin{array}{l}\text { Numerical correlation between the real parts of the roots or stable coefficients } \\
\text { for polynomial equations } \mathrm{P}(\mathrm{x}) \text { and } \mathrm{Q}(\mathrm{x}) \text {. }\end{array}$ \\
\hline$f_{\operatorname{Im}}:$ & $\begin{array}{l}\text { Numerical correlation between the imaginary parts of the roots or fixed terms } \\
\text { for polynomial equations } \mathrm{P}(\mathrm{x}) \text { and } \mathrm{Q}(\mathrm{x}) \text {. }\end{array}$ \\
\hline S: & Step which applies to the coefficients of $\mathrm{P}(\mathrm{x}), \mathrm{Q}(\mathrm{x})$ within the interval $[\mathrm{a}, \mathrm{b}]$. \\
\hline N: & $\begin{array}{l}\text { Number of different numbers that result for the coefficients of } \mathrm{P}(\mathrm{x}), \mathrm{Q}(\mathrm{x}) \\
\text { depending on the step } \mathrm{S} \text { within the interval }[a, b] \text {. }\end{array}$ \\
\hline $\mathrm{N}_{\mathrm{C}}$ : & $\begin{array}{l}\text { Number of coefficients of polynomial equations } \mathrm{P}(\mathrm{x}), \mathrm{Q}(\mathrm{x}) \text { within the interval } \\
{[\mathrm{a}, \mathrm{b}] \text {. }}\end{array}$ \\
\hline $\mathrm{N}_{\mathrm{EQ}}:$ & $\begin{array}{l}\text { Number of different polynomial equations } \mathrm{P}(\mathrm{x}), \mathrm{Q}(\mathrm{x}) \text { according with } \mathrm{S}, \mathrm{N}, \mathrm{N}_{\mathrm{C}} \\
\text { for the mathematical model. }\end{array}$ \\
\hline $\mathrm{R}^{2}$ : & Coefficient of determination of the numerical relationship. \\
\hline c: & Correlation coefficient of the numerical relationship between $\rho / \rho^{\prime}$ and $t / t^{\prime}$. \\
\hline $\mathrm{y}_{1} \ldots \mathrm{y}_{6}$ & Roots by radicals of the depressed sextic equation $\mathrm{G}(\mathrm{y})$ \\
\hline$\rho_{1}^{\prime} \ldots \rho_{6}^{\prime}$ & $\begin{array}{l}\text { Roots by radicals of the dependent sextic polynomial equation } \mathrm{Q}(\mathrm{x}) \text { in the terms } \\
\text { of equation (13). }\end{array}$ \\
\hline$\rho_{1 \mathrm{E}} \cdots \rho_{6 \mathrm{E}}:$ & $\begin{array}{l}\text { Exact roots of } \mathrm{P}(\mathrm{x}) \text {. Roots calculated using software, no algebraic radical } \\
\text { solution. }\end{array}$ \\
\hline$\rho_{1} \ldots \rho_{6}:$ & $\begin{array}{l}\text { Estimated roots of the given sextic polynomial equation } \mathrm{P}(\mathrm{x}) \text { by the resulting } \\
\text { mathematical model. }\end{array}$ \\
\hline$\rho_{1}, \rho_{1}^{\prime}:$ & The first of the six roots of polynomials $\mathrm{P}(\mathrm{x}), \mathrm{Q}(\mathrm{x})$ \\
\hline
\end{tabular}

\section{Introduction}

Historically, many different solutions have been proposed for equations with degree $\mathrm{n} \leq 4$; these solutions are all expressed and related to the coefficients of the equations. During the 17th and 18th centuries, mathematicians worked hard to find radical solutions to fifthdegree equations. Finally, it was proved that the polynomial equations with degree $n \geq 5$ in their complete form, cannot be solved with radicals; with solutions expressed in terms of the initial coefficients of the given equations. The above conclusion was partly formulated by $\mathrm{P}$. Ruffini in 1799 [1] and was finally proved by the Norwegian mathematician N. Abel in 1824 $[2,3]$; this theorem has received the name Abel-Ruffini theorem. In 1832 E. Galois with his theory formulated the conditions which define when the solutions of polynomial equations with degree $n \geq 5$ can be calculated radically [4].

The solution of a polynomial with radicals depends on the symmetry group of its roots on the Cartesian level and the Galois group to which the polynomial belongs. The French mathematician Evariste Galois died shortly after writing his theory which remained unclaimed; the documents were finally discovered by J. Liouville in 1843 [5]. Due to the fact that it was proved impossible to find radicals in polynomials with a higher than fifth degree, the interest of mathematicians in this field decreased significantly and any efforts from the 19th century onwards focused on finding reliable approximate models for estimating roots 
especially for quintic polynomial equations. Compared to fifth-degree or lower equations, there are not many references in finding solutions to general sextic polynomial equations. A general sextic polynomial equation $\mathrm{P}(\mathrm{x})$ is presented below (1), where $\alpha_{6} \neq 0$ and $\left\{\alpha_{1}, \alpha_{2}, \alpha_{3}, \alpha_{4}, \alpha_{5}, \alpha_{6}\right\} \in \mathbb{C}$.

$$
P(x)=x^{6}+\alpha_{1} x^{5}+\alpha_{2} x^{4}+\alpha_{3} x^{3}+\alpha_{4} x^{2}+\alpha_{5} x+\alpha_{6}=0
$$

Some forms of sextic polynomials can be solved radically, such as sextic polynomials that do not have a quintic term, a cubic term, and a primary term. Examples of these sextic polynomials follow (2) - (5).

$$
\begin{gathered}
\mathrm{x}^{6}+\alpha_{1} \mathrm{x}^{4}+\alpha_{2} \mathrm{x}^{2}+\alpha_{3}=0, \alpha_{3} \neq 0 \\
\mathrm{x}^{6}+\alpha_{1} \mathrm{x}^{2}+\alpha_{2}=0, \alpha_{2} \neq 0 \\
\mathrm{x}^{6}+\alpha_{1} \mathrm{x}^{4}+\alpha_{2}=0, \alpha_{2} \neq 0 \\
\mathrm{x}^{6}+\alpha_{1} \mathrm{x}^{3}+\alpha_{2}=0, \alpha_{2} \neq 0
\end{gathered}
$$

These forms can be solved radically with the help of transformations which transform the polynomials into cubic and secondary equations; with degree $n \leq 3$, which in turn are solved by classical algebraic procedures such as the formula of G. Cardano, L. Ferrari, N. Tartaglia [6]. On the contrary, sixth-degree polynomials containing at least two of the primary, cubic, or quintic terms cannot be transformed and therefore solved by algebraic procedures and radicals. From a mathematical point of view, the definition of the Galois groups to which the various forms of sextic polynomial equations belong, is interesting. Brown et al., (2013), examine the sextic trinomial of Bring - Jerrard $x^{6}+\alpha_{1} x+\alpha_{2}$, with Galois groups $\mathrm{C}_{6}, \mathrm{C}_{3}$ or $\mathrm{C}_{3} \times \mathrm{S}_{3}$ [7], o Cavallo, (2019) [8], examines the Galois groups for the symmetric trinomial of equation (5), while Awtrey, (2019) examines the Galois group of the irreducible sextic polynomial of equation (2) [9].

Every polynomial equation with degree $n \leq 4$ has a resolvent; the equation through which the definition of the radicals is achieved. The resolvent usually has a degree $n-1$ with regard to the degree of the polynomial equation to be solved; in quadratic equations for example a third-degree resolvent results, but in some cases the resolvent may have a higher degree than the polynomial equation under consideration; for instance quintic equations that can result in a sextic resolvent [10]. Resolvents exist in the Galois Theory as well for the definition of the Galois group of a polynomial. If a polynomial $\mathrm{P}(\mathrm{x})$ has a Galois group $\mathrm{p} / \mathrm{p}$ $\subset \mathrm{G}$ then group $\mathrm{G}$ has a resolvent with coefficients that are numerically related to the polynomial $\mathrm{P}(\mathrm{x})$. Research on Galois group resolvents has been conducted by Girstmair, (1983) [11], Hurley and Head, (1987) [12].

Awtrey et al., (2015) deal with the resolvents of irreducible polynomials [13], while Harringhton and Jones, (2017) examine the conditions whether a sextic polynomial becomes irreducible or reducible and the identification of its Galois groups without a resolvent for these specific groups [14]. Regarding other methodologies for the determination of the roots of sextic polynomial equations, Hagedorn, (2000) cites a generalized model for the determination of roots in irreducible polynomials belonging to group $G$ as well as the conditions for the determination of Galois groups [15], while Boswell and Glasser, (2005) report the solvability criteria with radicals in irreducible sextic polynomials with rational coefficients in the set of complex numbers $\mathbb{C}[\mathbf{1 6}]$.

The study of A.B. Coble deserves special mention in this article. Coble, (1911a) [17, 22] cites an earlier study by Professor Felix Klein, in which the development of a methodology is presented for solving the general sextic equation associated with the Valentiner form-problem. This methodology makes a clear distinction between classical algebraic processes and the field of transcendental number theory [21]. Coble, through the 
hypergeometric series and the solution of a quintic polynomial, describes a model for deriving the roots of a particular set of sextic polynomial equations. The Valentiner form-problem was formulated in 1889 [18] and is related to the Galois Theory of groups. It consists of a system of three equations with six variables which have square and cubic roots, where these six points defined by the system of equations form the alternating group [17]. In his second paper, Coble, $(1911 b)[\mathbf{1 9}, \mathbf{2 2}]$ deals with the application of Moore's cross-ratio group to solve the sextic equation. In Euclidean geometry, cross-ratio or double-ratio is called the ratio of the products of the lengths of linear segments which are formed by the separation of two random lines $\varepsilon_{1}$ and $\varepsilon_{2}$ into three straight segments from four other lines which pass through a common point and intersect $\tau 1 \zeta \varepsilon_{1}$ and $\varepsilon_{2}$.

E.H. Moore in 1900, proposed that the cross-ratio can be defined as an explicit function of four independent variables that express the geometric proportions of straight segments; the cross-ratio can be defined in four different ways based on F. Klein's theory of sextic equations [21], and in six different ways based on the Cremona cross-ratio group $\mathrm{C}_{\mathrm{n} \text { !; }}$; the group $S_{n-3}$ of order $n$ ! which is isomorphic to the permutation group of $n$ things [20].

Coble applied Moore's proposition for $n=6 !$ and $n=6 ! / 2$, initially considers six roots $\mathrm{z}_{1} \ldots \mathrm{z}_{6}$ which are transformed into $\mathrm{y}_{1} \ldots \mathrm{y}_{6} /\left\{\mathrm{y}_{6} \rightarrow \infty \kappa \alpha \sum_{i}^{5} y_{i}=0\right\}$, and at the end of the research comes up with a depressed cubic polynomial with two quadratic trinomials to be solved as coefficients.

In addition, one type of function that contributes to the methods of solving sextic equations is the Kampé de Fériet functions, which are a generalized expression of two variables of the hypergeometric series [21]. Finally, Mochimaru, (2005) describes an interesting algebraic process for the analysis and extraction of radicals in the general sextic equation based on the Lagrangean formula, the hypergeometric series and the possibility of reciprocal solution [23]. Kulkarni, (2008) solves the sextic equation and extracts roots using the polynomial decomposition method [24]. The aforementioned literature is a theoretical background for the development of computational tools for estimating and calculating the roots of sextic polynomial equations. Indicatively, Crass, (1999) develops an iteration algorithm for the determination of solutions of the general sextic equation based on the alternating group $\mathrm{A}_{6}$ which derives from the Valentiner form-problem and the corresponding iteration algorithm of Doyle and McMullen for the determination of roots in the quintic equations $[25,26]$.

\section{Development of methodology}

\subsection{First part, solution of a depressed sextic equation under certain conditions}

The first stage of the methodology describes the solution of a depressed sextic equation with radicals. The basic condition for its solution is the equality of its constant term with the other coefficients of the equation. In the general sextic polynomial equation (1), we use the corresponding transform that Vieta first applied to the quadratic equations, this time to eliminate the quintic term. If we set the transformation $\mathrm{x}=\mathrm{y}-\alpha_{1} / 6$, the following depressed sextic equation $\mathrm{G}(\mathrm{y})$ is derived, where $t \neq 0(6)$ and $\{p, q, r, s, t\} \in \mathbb{C}$.

$$
G(y)=y^{6}+p y^{4}+q y^{3}+r y^{2}+s y+t=0
$$

The coefficients of (6) are numerically related to the coefficients of the original equation (1) as follows:

$\mathrm{p}=-\frac{5 \alpha_{1}^{2}}{12}+\alpha_{2}$ 
$\mathrm{q}=\frac{5 \alpha_{1}^{3}}{27}-\frac{2 \alpha_{1} \alpha_{2}}{3}+\alpha_{3}$

$r=-\frac{5 \alpha_{1}^{4}}{144}+\frac{\alpha_{1}^{2} \alpha_{2}}{6}-\frac{\alpha_{1} \alpha_{3}}{2}+\alpha_{4}$

$\mathrm{s}=\frac{\alpha_{1}^{5}}{324}-\frac{\alpha_{1}^{3} \alpha_{2}}{54}+\frac{\alpha_{1}^{2} \alpha_{3}}{12}-\frac{\alpha_{1} \alpha_{4}}{3}$

$\mathrm{t}=-\frac{5 \alpha_{1}^{6}}{46656}+\frac{\alpha_{1}^{4} \alpha_{2}}{1296}-\frac{\alpha_{1}^{3} \alpha_{3}}{216}+\frac{\alpha_{1}^{2} \alpha_{4}}{36}+\frac{\alpha_{1} \alpha_{5}}{6}+\alpha_{6}$

It is assumed that equation (6) is reducible and is formed by the product of two cubic trinomials without quadratic terms that are solvable with the Cardano formulas. Hence, the equation (6) can be expressed as follows:

$$
G(y)=\left(y^{3}+m y+n\right)\left(y^{3}+u y+v\right)=0
$$

In equation (7), the coefficients $m, n, u, v$ are unknown numbers. If equation (7) is solved, then equation (8) results a depressed sextic polynomial equation.

$$
\mathrm{G}(\mathrm{y})=\mathrm{y}^{6}+(\mathrm{m}+\mathrm{u}) \mathrm{y}^{4}+(\mathrm{n}+\mathrm{v}) \mathrm{y}^{3}+\mathrm{muy}^{2}+(\mathrm{mv}+\mathrm{nu}) \mathrm{y}+\mathrm{nv}=0
$$

The equation (6) is identical with (8), so the coefficients of the equations can be equated and the unknowns can be calculated as $\{\mathrm{m}, \mathrm{n}, \mathrm{u}, \mathrm{v}\}=\mathrm{f}(\mathrm{p}, \mathrm{q}, \mathrm{r}, \mathrm{s}, \mathrm{t})$. Due to the fact that the system of equations is a $5 \times 4$ system, an additional equation arises which is the necessary condition for equation (6) to be solved with radicals. The $5 \times 4$ system is as follows:

$$
\begin{gathered}
\mathrm{m}+\mathrm{u}=\mathrm{p} \\
\mathrm{n}+\mathrm{v}=\mathrm{q} \\
\mathrm{mu}=\mathrm{r} \\
\mathrm{mv}+\mathrm{nu}=\mathrm{s} \\
\mathrm{nv}=\mathrm{t}
\end{gathered}
$$

From the above system the solutions of $\mathrm{m}, \mathrm{n}, \mathrm{u}, \mathrm{v}$ and an equation from the relation $\mathrm{nv}=\mathrm{t}$ arise.

$$
\begin{aligned}
& \mathrm{m}=\frac{\mathrm{p}}{2} \pm \sqrt{\frac{\mathrm{p}^{2}}{4}-\mathrm{r}}(9), \quad \mathrm{n}=\frac{\mathrm{q}}{2} \pm \sqrt{\frac{\mathrm{q}^{2}}{4}-\mathrm{t}} \\
& \mathrm{u}=\frac{\mathrm{p}}{2} \pm \sqrt{\frac{\mathrm{p}^{2}}{4}-\mathrm{r}}(11), \quad \mathrm{v}=\frac{\mathrm{q}}{2} \pm \sqrt{\frac{\mathrm{q}^{2}}{4}-\mathrm{t}} \\
& \mathrm{t}=\frac{\mathrm{q}^{2}}{4}-\frac{(\mathrm{pq}-2 \mathrm{~s})^{2}}{4\left(\mathrm{p}^{2}-4 \mathrm{r}\right)}
\end{aligned}
$$

It is found that $m=u$ and $n=v$. Substituting solutions (9) to (12) in (7) results in two pairs of two equations with equal coefficients. The two different equations (14) and (15) of 
each pair are cubic trinomials. The solutions of $\mathrm{G}(\mathrm{y})$ are given by the roots of equations (14) and (15).

$$
\begin{aligned}
& \mathrm{y}^{3}+\left(\frac{\mathrm{p}}{2}+\sqrt{\frac{\mathrm{p}^{2}}{4}-\mathrm{r}}\right) \mathrm{y}+\left(\frac{\mathrm{q}}{2}+\sqrt{\frac{\mathrm{q}^{2}}{4}-\mathrm{t}}\right)=0 \\
& \mathrm{y}^{3}+\left(\frac{\mathrm{p}}{2}-\sqrt{\frac{\mathrm{p}^{2}}{4}-\mathrm{r}}\right) \mathrm{y}+\left(\frac{\mathrm{q}}{2}-\sqrt{\frac{\mathrm{q}^{2}}{4}-\mathrm{t}}\right)=0
\end{aligned}
$$

A condition so that calculation of the roots (16) to (25) is valid, is the equality of the coefficients in (13). Also, the following additional restriction arises from the equation (13); $\mathrm{p}^{2}-4 \mathrm{r} \neq 0 \Leftrightarrow \mathrm{p}^{2} \neq 4 \mathrm{r} \Leftrightarrow \mathrm{p} \neq \pm 2 \sqrt{\mathrm{r}}$.

The solutions of equation (6), $y_{1} \ldots \mathrm{y}_{6}$, are the following:

$$
\begin{aligned}
& y_{1}=\sqrt[3]{-\frac{\mathrm{q}}{4}-\frac{\sqrt{\Delta_{1}}}{2}+\sqrt{\Delta_{3}}}+\sqrt[3]{-\frac{\mathrm{q}}{4}-\frac{\sqrt{\Delta_{1}}}{2}-\sqrt{\Delta_{3}}} \\
& y_{2}=\omega_{1} \sqrt[3]{-\frac{\mathrm{q}}{4}-\frac{\sqrt{\Delta_{1}}}{2}+\sqrt{\Delta_{3}}}+\omega_{2} \sqrt[3]{-\frac{\mathrm{q}}{4}-\frac{\sqrt{\Delta_{1}}}{2}-\sqrt{\Delta_{3}}} \\
& \mathrm{y}_{3}=\omega_{2} \sqrt[3]{-\frac{\mathrm{q}}{4}-\frac{\sqrt{\Delta_{1}}}{2}+\sqrt{\Delta_{3}}}+\omega_{1} \sqrt[3]{-\frac{\mathrm{q}}{4}-\frac{\sqrt{\Delta_{1}}}{2}-\sqrt{\Delta_{3}}} \\
& \mathrm{y}_{4}=\sqrt[3]{-\frac{\mathrm{q}}{4}+\frac{\sqrt{\Delta_{1}}}{2}+\sqrt{\Delta_{4}}}+\sqrt[3]{-\frac{\mathrm{q}}{4}+\frac{\sqrt{\Delta_{1}}}{2}-\sqrt{\Delta_{4}}} \\
& \mathrm{y}_{5}=\omega_{1} \sqrt[3]{-\frac{\mathrm{q}}{4}+\frac{\sqrt{\Delta_{1}}}{2}+\sqrt{\Delta_{4}}}+\omega_{2} \sqrt[3]{-\frac{\mathrm{q}}{4}+\frac{\sqrt{\Delta_{1}}}{2}-\sqrt{\Delta_{4}}} \\
& \mathrm{y}_{6}=\omega_{2} \sqrt[3]{-\frac{\mathrm{q}}{4}+\frac{\sqrt{\Delta_{1}}}{2}+\sqrt{\Delta_{4}}}+\omega_{1} \sqrt[3]{-\frac{\mathrm{q}}{4}+\frac{\sqrt{\Delta_{1}}}{2}-\sqrt{\Delta_{4}}}
\end{aligned}
$$

$\Delta_{1}$ to $\Delta_{4}$ are the discriminants of the polynomial equation (6) and $\omega_{1}, \omega_{2}$ are the cubic roots of unity. $\Delta_{1}$ and $\Delta_{2}$ are the main discriminants, while $\Delta_{3}$ and $\Delta_{4}$ are the secondary discriminants of $\mathrm{G}(\mathrm{y})$ which are dependent since $\left\{\Delta_{3}, \Delta_{4}\right\}=\mathrm{f}\left(\Delta_{1}, \Delta_{2}\right)$.

$$
\Delta_{1}=\frac{\mathrm{q}^{2}}{4}-\mathrm{t}(22), \quad \Delta_{2}=\frac{\mathrm{p}^{2}}{4}-\mathrm{r}
$$




$$
\begin{aligned}
& \Delta_{3}=\left(\frac{\mathrm{q}}{4}+\frac{\sqrt{\Delta_{1}}}{2}\right)^{2}+\left(\frac{\mathrm{p}}{6}+\frac{\sqrt{\Delta_{2}}}{3}\right)^{3} \\
& \Delta_{4}=\left(\frac{\mathrm{q}}{4}-\frac{\sqrt{\Delta_{1}}}{2}\right)^{2}+\left(\frac{\mathrm{p}}{6}-\frac{\sqrt{\Delta_{2}}}{3}\right)^{3}
\end{aligned}
$$

Discriminants $\Delta_{1}, \Delta_{3}, \Delta_{4}$ define directly the type of roots (16) - (21) of G(y), which are calculated algebraically through equations (14) and (15). In Table 1 all the possible outcomes that form the type of roots of the depressed sextic polynomial equation (6) are presented.

\begin{tabular}{|c|c|c|c|c|}
\hline \multicolumn{2}{|c|}{ Independent discriminant } & \multicolumn{2}{|c|}{ Dependent discriminant } & \multirow{2}{*}{\begin{tabular}{|l|} 
Roots \\
$\rho_{1} \ldots \rho_{6}$ \\
\end{tabular}} \\
\hline$\Delta_{1}$ & $\Delta_{2}$ & $\Delta_{3}$ & $\Delta_{4}$ & \\
\hline$\in(-\infty, 0)$ & $\in(-\infty, 0)$ & $\in(-\infty, 0)$ & $\in(-\infty, 0)$ & $\rho_{1} \ldots \rho_{6} \in C$ \\
\hline$\in(-\infty, 0)$ & $\in(-\infty, 0)$ & $\in(-\infty, 0)$ & 0 & $\rho_{1} \ldots \rho_{6} \in C$ \\
\hline$\in(-\infty, 0)$ & $\in(-\infty, 0)$ & $\in(-\infty, 0)$ & $\in(0,+\infty)$ & $\rho_{1} \ldots \rho_{6} \in C$ \\
\hline$\in(-\infty, 0)$ & $\in(-\infty, 0)$ & 0 & $\in(-\infty, 0)$ & $\rho_{1} \ldots \rho_{6} \in C$, one double complex root \\
\hline$\in(-\infty, 0)$ & $\in(-\infty, 0)$ & 0 & 0 & $\rho_{1} \ldots \rho_{6} \in C$, two double complex roots \\
\hline$\in(-\infty, 0)$ & $\in(-\infty, 0)$ & 0 & $\in(0,+\infty)$ & $\rho_{1} \ldots \rho_{6} \in C$, one double complex root \\
\hline$\in(-\infty, 0)$ & $\in(-\infty, 0)$ & $\in(0,+\infty)$ & $\in(-\infty, 0)$ & $\rho_{1} \ldots \rho_{6} \in C$ \\
\hline$\in(-\infty, 0)$ & $\in(-\infty, 0)$ & $\in(0,+\infty)$ & 0 & $\rho_{1} \ldots \rho_{6} \in C$, one double complex root \\
\hline$\in(-\infty, 0)$ & $\in(-\infty, 0)$ & $\in(0,+\infty)$ & $\in(0,+\infty)$ & $\rho_{1} \ldots \rho_{6} \in C$ \\
\hline$\in(-\infty, 0)$ & 0 & $\in(-\infty, 0)$ & $\in(-\infty, 0)$ & $\rho_{1} \ldots \rho_{6} \in C$ \\
\hline$\in(-\infty, 0)$ & 0 & $\in(-\infty, 0)$ & 0 & $\rho_{1} \ldots \rho_{6} \in C$, one double complex root \\
\hline$\in(-\infty, 0)$ & 0 & $\in(-\infty, 0)$ & $\in(0,+\infty)$ & $\rho_{1} \ldots \rho_{6} \in C$ \\
\hline$\in(-\infty, 0)$ & 0 & 0 & $\in(-\infty, 0)$ & $\rho_{1} \ldots \rho_{6} \in C$, one double complex root \\
\hline$\in(-\infty, 0)$ & 0 & 0 & 0 & $\rho_{1} \ldots \rho_{6} \in \mathrm{C}$, two double complex roots \\
\hline$\in(-\infty, 0)$ & 0 & 0 & $\in(0,+\infty)$ & $\rho_{1} \ldots \rho_{6} \in \mathrm{C}$, one double complex root \\
\hline$\in(-\infty, 0)$ & 0 & $\in(0,+\infty)$ & $\in(-\infty, 0)$ & $\rho_{1} \ldots \rho_{6} \in C$ \\
\hline$\in(-\infty, 0)$ & 0 & $\in(0,+\infty)$ & 0 & $\rho_{1} \ldots \rho_{6} \in C$, one double complex root \\
\hline$\in(-\infty, 0)$ & 0 & $\in(0,+\infty)$ & $\in(0,+\infty)$ & $\rho_{1} \ldots \rho_{6} \in C$ \\
\hline$\in(-\infty, 0)$ & $\in(0,+\infty)$ & $\in(-\infty, 0)$ & $\in(-\infty, 0)$ & $\rho_{1} \ldots \rho_{6} \in C$ \\
\hline$\in(-\infty, 0)$ & $\in(0,+\infty)$ & $\in(-\infty, 0)$ & 0 & $\rho_{1} \ldots \rho_{6} \in C$, one double complex root \\
\hline$\in(-\infty, 0)$ & $\in(0,+\infty)$ & $\in(-\infty, 0)$ & $\in(0,+\infty)$ & $\rho_{1} \ldots \rho_{6} \in C$ \\
\hline$\in(-\infty, 0)$ & $\in(0,+\infty)$ & 0 & $\in(-\infty, 0)$ & $\rho_{1} \ldots \rho_{6} \in C$, one double complex root \\
\hline$\in(-\infty, 0)$ & $\in(0,+\infty)$ & 0 & 0 & $\rho_{1} \ldots \rho_{6} \in \mathrm{C}$, two double complex roots \\
\hline$\in(-\infty, 0)$ & $\in(0,+\infty)$ & 0 & $\in(0,+\infty)$ & $\rho_{1} \ldots \rho_{6} \in \mathrm{C}$, one double complex root \\
\hline$\in(-\infty, 0)$ & $\in(0,+\infty)$ & $\in(0,+\infty)$ & $\in(-\infty, 0)$ & $\rho_{1} \ldots \rho_{6} \in C$ \\
\hline$\in(-\infty, 0)$ & $\in(0,+\infty)$ & $\in(0,+\infty)$ & 0 & $\rho_{1} \ldots \rho_{6} \in C$, one double complex root \\
\hline$\in(-\infty, 0)$ & $\in(0,+\infty)$ & $\in(0,+\infty)$ & $\in(0,+\infty)$ & $\rho_{1} \ldots \rho_{6} \in C$ \\
\hline 0 & $\in(-\infty, 0)$ & $\in(-\infty, 0)$ & $\in(-\infty, 0)$ & $\rho_{1} \ldots \rho_{6} \in C$ \\
\hline 0 & $\in(-\infty, 0)$ & $\in(-\infty, 0)$ & 0 & $\rho_{1} \ldots \rho_{6} \in C$, one double complex root \\
\hline 0 & $\in(-\infty, 0)$ & $\in(-\infty, 0)$ & $\in(0,+\infty)$ & $\rho_{1} \ldots \rho_{6} \in \mathrm{C}$ \\
\hline 0 & $\in(-\infty, 0)$ & 0 & $\in(-\infty, 0)$ & $\rho_{1} \ldots \rho_{6} \in C$, one double complex root \\
\hline 0 & $\in(-\infty, 0)$ & 0 & 0 & $\begin{array}{c}\rho_{1} \ldots \rho_{6} \in \mathrm{C} \text {, one double complex root and one } \\
\text { quadruple complex root }\end{array}$ \\
\hline 0 & $\in(-\infty, 0)$ & 0 & $\in(0,+\infty)$ & $\rho_{1} \ldots \rho_{6} \in \mathrm{C}$, one double complex root \\
\hline 0 & $\in(-\infty, 0)$ & $\in(0,+\infty)$ & $\in(-\infty, 0)$ & $\rho_{1} \ldots \rho_{6} \in C$ \\
\hline 0 & $\in(-\infty, 0)$ & $\in(0,+\infty)$ & 0 & $\rho_{1} \ldots \rho_{6} \in \mathrm{C}$, one double complex root \\
\hline 0 & $\in(-\infty, 0)$ & $\in(0,+\infty)$ & $\in(0,+\infty)$ & $\begin{array}{l}\text { Four complex roots and two roots which are } \\
\text { dependent by quantities }-0.25 q \pm \sqrt{\Delta_{3}} \text { and } \\
\qquad-0.25 q \pm \sqrt{\Delta_{4}}\end{array}$ \\
\hline 0 & 0 & $\in(-\infty, 0)$ & $\in(-\infty, 0)$ & $\rho_{1} \ldots \rho_{6} \in \mathrm{C}$ \\
\hline 0 & 0 & $\in(-\infty, 0)$ & 0 & $\rho_{1} \ldots \rho_{6} \in C$, one double complex root \\
\hline 0 & 0 & $\in(-\infty, 0)$ & $\in(0,+\infty)$ & $\rho_{1} \ldots \rho_{6} \in C$, one double complex root \\
\hline
\end{tabular}

Table 1. Investigation of the roots of equation (6) according to the discriminants $\Delta_{1}-\Delta_{4}$. 


\begin{tabular}{|c|c|c|c|c|}
\hline 0 & 0 & 0 & $\in(-\infty, 0)$ & $\rho_{1} \ldots \rho_{6} \in \mathrm{C}$, one double complex root \\
\hline 0 & 0 & 0 & 0 & $\begin{array}{l}\text { One double root and one quadruple root. If } q<0 \\
\text { then } \rho_{1} \ldots \rho_{6} \in \mathrm{R} \text {, if } \mathrm{q}>0 \text { then } \rho_{1} \ldots \rho_{6} \in \mathrm{C} \text {. }\end{array}$ \\
\hline 0 & 0 & 0 & $\in(0,+\infty)$ & $\begin{array}{l}\text { One double root. If } q<0 \text { then } \rho_{1} \ldots \rho_{6} \in \mathrm{R} \text {, if } \mathrm{q} \\
\quad>0 \text { then } \rho_{1} \ldots \rho_{6} \in \mathrm{C} .\end{array}$ \\
\hline 0 & 0 & $\in(0,+\infty)$ & $\in(-\infty, 0)$ & $\begin{array}{l}\text { Three complex roots and three other roots which } \\
\text { are dependent by quantity }-0.25 \mathrm{q} \pm \sqrt{\Delta_{3}}\end{array}$ \\
\hline 0 & 0 & $\in(0,+\infty)$ & 0 & $\begin{array}{l}\text { One double root which is real if } \mathrm{q}<0 \text { and } \\
\text { complex if } \mathrm{q}>0 \text {. Four other roots which are } \\
\text { dependent by quantity }-0.25 \mathrm{q} \pm \sqrt{\Delta_{3}}\end{array}$ \\
\hline 0 & 0 & $\in(0,+\infty)$ & $\in(0,+\infty)$ & $\begin{array}{l}\text { The roots are dependent by quantities } \\
-0.25 q \pm \sqrt{\Delta_{3}} \text { and }-0.25 q \pm \sqrt{\Delta_{4}}\end{array}$ \\
\hline 0 & $\in(0,+\infty)$ & $\in(-\infty, 0)$ & $\in(-\infty, 0)$ & $\rho_{1} \ldots \rho_{6} \in C$ \\
\hline 0 & $\in(0,+\infty)$ & $\in(-\infty, 0)$ & 0 & $\begin{array}{l}\text { One double root and one other which are real if } \\
\mathrm{q}<0 \text { and complex if } \mathrm{q}>0 \text {. Three other complex } \\
\text { roots. }\end{array}$ \\
\hline 0 & $\in(0,+\infty)$ & $\in(-\infty, 0)$ & $\in(0,+\infty)$ & $\begin{array}{l}\text { Three complex roots and three other which are } \\
\text { dependent by quantity }-0.25 q \pm \sqrt{\Delta_{4}}\end{array}$ \\
\hline 0 & $\in(0,+\infty)$ & 0 & $\in(-\infty, 0)$ & $\begin{array}{c}\text { One double root and one other which are real if } \\
\mathrm{q}<0 \text { and complex if } \mathrm{q}>0 \text {. Three other complex } \\
\text { roots. }\end{array}$ \\
\hline 0 & $\in(0,+\infty)$ & 0 & 0 & $\begin{array}{l}\text { One double root and one quadruple root. If } \mathrm{q}<0 \\
\text { then } \rho_{1} \ldots \rho_{6} \in \mathrm{R} \text {, if } \mathrm{q}>0 \text { then } \rho_{1} \ldots \rho_{6} \in \mathrm{C} \text {. }\end{array}$ \\
\hline 0 & $\in(0,+\infty)$ & 0 & $\in(0,+\infty)$ & $\begin{array}{l}\text { Three roots which are dependent by quantity } \\
-0.25 q \pm \sqrt{\Delta_{4}} \text { and three other roots which are } \\
\text { real if } q<0 \text { and complex if } q>0 \text {. }\end{array}$ \\
\hline 0 & $\in(0,+\infty)$ & $\in(0,+\infty)$ & $\in(-\infty, 0)$ & $\begin{array}{l}\text { Three complex roots and three other roots which } \\
\text { dependent by quantity }-0.25 \mathrm{q} \pm \sqrt{\Delta_{3}}\end{array}$ \\
\hline 0 & $\in(0,+\infty)$ & $\in(0,+\infty)$ & 0 & $\begin{array}{l}\text { One double root and one other which are real if } \\
\mathrm{q}<0 \text { and complex if } \mathrm{q}>0 \text {. Three other complex } \\
\text { roots. Three other roots which are dependent by } \\
\text { quantity }-0.25 \mathrm{q} \pm \sqrt{\Delta_{3}}\end{array}$ \\
\hline 0 & $\in(0,+\infty)$ & $\in(0,+\infty)$ & $\in(0,+\infty)$ & $\begin{array}{l}\text { The roots are dependent by quantities } \\
-0.25 \mathrm{q} \pm \sqrt{\Delta_{3}} \text { and }-0.25 \mathrm{q} \pm \sqrt{\Delta_{4}}\end{array}$ \\
\hline$\in(0,+\infty)$ & $\in(-\infty, 0)$ & $\in(-\infty, 0)$ & $\in(-\infty, 0)$ & $\rho_{1} \ldots \rho_{6} \in C$ \\
\hline$\in(0,+\infty)$ & $\in(-\infty, 0)$ & $\in(-\infty, 0)$ & 0 & $\begin{array}{l}\text { Three complex roots and three other roots which } \\
\text { are complex if }-0.25 q+0.5 \sqrt{\Delta_{1}}<0 \text { and real if } \\
\qquad-0.25 q+0.5 \sqrt{\Delta_{1}}>0\end{array}$ \\
\hline$\in(0,+\infty)$ & $\in(-\infty, 0)$ & $\in(-\infty, 0)$ & $\in(0,+\infty)$ & $\begin{array}{l}\text { Three complex roots and three other roots which } \\
\text { are dependent by quantity } \\
-0.25 q+0.5 \sqrt{\Delta_{1}} \pm \sqrt{\Delta_{4}}\end{array}$ \\
\hline$\in(0,+\infty)$ & $\in(-\infty, 0)$ & 0 & $\in(-\infty, 0)$ & $\begin{array}{l}\text { Three complex roots and three other roots which } \\
\text { are dependent by quantity }-0.25 q-0.5 \sqrt{\Delta_{1}}\end{array}$ \\
\hline$\in(0,+\infty)$ & $\in(-\infty, 0)$ & 0 & 0 & $\begin{array}{c}\text { Two double roots and two other roots which are } \\
\text { dependent by quantity }-0.25 q \pm 0.5 \sqrt{\Delta_{1}}\end{array}$ \\
\hline$\in(0,+\infty)$ & $\in(-\infty, 0)$ & 0 & $\in(0,+\infty)$ & $\begin{array}{c}\text { One double root and one other which are real if } \\
-0.25 q-0.5 \sqrt{\Delta_{1}}>0 \text { and complex if } \\
-0.25 q-0.5 \sqrt{\Delta_{1}}<0 \text {. Three other roots. }\end{array}$ \\
\hline$\in(0,+\infty)$ & $\in(-\infty, 0)$ & $\in(0,+\infty)$ & $\in(-\infty, 0)$ & $\rho_{1} \ldots \rho_{6} \in C$ \\
\hline$\in(0,+\infty)$ & $\in(-\infty, 0)$ & $\in(0,+\infty)$ & 0 & $\begin{array}{c}\text { Two roots which are dependent by quantities } \\
-0.25 q+0.5 \sqrt{\Delta_{1}} \text { and }-0.25 q-0.5 \sqrt{\Delta_{1}} \pm \\
\sqrt{\Delta_{3}} \text {. One double root which is real if }-0.25 q- \\
0.5 \sqrt{\Delta_{1}}>0 \text { and complex if }-0.25 q- \\
0.5 \sqrt{\Delta_{1}}<0 \text {. Two other roots. }\end{array}$ \\
\hline$\in(0,+\infty)$ & $\in(-\infty, 0)$ & $\in(0,+\infty)$ & $\in(0,+\infty)$ & $\begin{array}{c}\text { Two roots which are dependent by quantities } \\
-0.25 q-0.5 \sqrt{\Delta_{1}} \pm \sqrt{\Delta_{3}} \text { and }-0.25 q+ \\
0.5 \sqrt{\Delta_{1}} \pm \sqrt{\Delta_{4}} \text {. Four other complex roots. }\end{array}$ \\
\hline$\in(0,+\infty)$ & 0 & $\in(-\infty, 0)$ & $\in(-\infty, 0)$ & $\rho_{1} \ldots \rho_{6} \in C$ \\
\hline$\in(0,+\infty)$ & 0 & $\in(-\infty, 0)$ & ( & $\begin{array}{l}\text { Three complex roots, one double root and one } \\
\text { other root which are dependent by quantity }\end{array}$ \\
\hline
\end{tabular}




\begin{tabular}{|c|c|c|c|c|}
\hline & & & & $-0.25 q+0.5 \sqrt{\Delta_{1}}$ \\
\hline$\in(0,+\infty)$ & 0 & $\in(-\infty, 0)$ & $\in(0,+\infty)$ & $\begin{array}{l}\text { Three complex roots and three other roots which } \\
\text { are dependent by quantity } \\
-0.25 q+0.5 \sqrt{\Delta_{1}} \pm \sqrt{\Delta_{4}}\end{array}$ \\
\hline$\in(0,+\infty)$ & 0 & 0 & $\in(-\infty, 0)$ & $\begin{array}{l}\text { Three complex roots and three other roots which } \\
\text { are real if }-0.25 q-0.5 \sqrt{\Delta_{1}}>0 \text { and complex } \\
\text { if }-0.25 q-0.5 \sqrt{\Delta_{1}}<0 .\end{array}$ \\
\hline$\in(0,+\infty)$ & 0 & 0 & 0 & $\begin{array}{l}\text { Two double roots and two other roots which are } \\
\text { dependent by quantity }-0.25 q \pm 0.5 \sqrt{\Delta_{1}} \text {. }\end{array}$ \\
\hline$\in(0,+\infty)$ & 0 & 0 & $\in(0,+\infty)$ & $\begin{array}{l}\text { One double root and one other root which are } \\
\text { real if }-0.25 q-0.5 \sqrt{\Delta_{1}}>0 \text { and complex if } \\
\qquad 0.25 q-0.5 \sqrt{\Delta_{1}}<0 \text {. } \\
\text { Three roots which are dependent by quantity } \\
-0.25 q+0.5 \sqrt{\Delta_{1}} \pm \sqrt{\Delta_{4}}\end{array}$ \\
\hline$\in(0,+\infty)$ & 0 & $\in(0,+\infty)$ & $\in(-\infty, 0)$ & $\begin{array}{c}\text { Three complex roots and three others which are } \\
\text { dependent by quantity }-0.25 q-0.5 \sqrt{\Delta_{1}} \pm \\
\sqrt{\Delta_{3}} .\end{array}$ \\
\hline$\in(0,+\infty)$ & 0 & $\in(0,+\infty)$ & 0 & $\begin{array}{l}\text { One double root and one other which are real if } \\
-0.25 q+0.5 \sqrt{\Delta_{1}}>0 \text { and complex if } \\
\qquad-0.25 q+0.5 \sqrt{\Delta_{1}}<0 \\
\text { Three other roots which are dependent by } \\
\text { quantity }-0.25 q-0.5 \sqrt{\Delta_{1}} \pm \sqrt{\Delta_{3}} .\end{array}$ \\
\hline$\in(0,+\infty)$ & 0 & $\in(0,+\infty)$ & $\in(0,+\infty)$ & $\begin{array}{c}\text { Three roots which are dependent by quantity } \\
-0.25 q-0.5 \sqrt{\Delta_{1}} \pm \sqrt{\Delta_{3}} \text { and three other } \\
\text { which are dependent by quantity } \\
-0.25 q+0.5 \sqrt{\Delta_{1}} \pm \sqrt{\Delta_{4}}\end{array}$ \\
\hline$\in(0,+\infty)$ & $\in(0,+\infty)$ & $\in(-\infty, 0)$ & $\in(-\infty, 0)$ & $\rho_{1} \ldots \rho_{6} \in C$ \\
\hline$\in(0,+\infty)$ & $\in(0,+\infty)$ & $\in(-\infty, 0)$ & 0 & $\begin{array}{l}\text { Three complex roots. One double root and one } \\
\text { other which are real if }-0.25 q+0.5 \sqrt{\Delta_{1}}>0 \\
\text { and complex if }-0.25 q+0.5 \sqrt{\Delta_{1}}<0 \text {. }\end{array}$ \\
\hline$\in(0,+\infty)$ & $\in(0,+\infty)$ & $\in(-\infty, 0)$ & $\in(0,+\infty)$ & $\begin{array}{l}\text { Three complex roots and three others which are } \\
\text { dependent by quantity } \\
-0.25 q+0.5 \sqrt{\Delta_{1}} \pm \sqrt{\Delta_{4}} .\end{array}$ \\
\hline$\in(0,+\infty)$ & $\in(0,+\infty)$ & 0 & $\in(-\infty, 0)$ & $\begin{array}{l}\text { Three complex roots. One double root and one } \\
\text { other which are real if }-0.25 q-0.5 \sqrt{\Delta_{1}}>0 \\
\text { and complex if }-0.25 q-0.5 \sqrt{\Delta_{1}}<0 \text {. }\end{array}$ \\
\hline$\in(0,+\infty)$ & $\in(0,+\infty)$ & 0 & 0 & $\begin{array}{l}\text { Two double roots and two other roots which are } \\
\text { dependent by quantity }-0.25 q \pm 0.5 \sqrt{\Delta_{1}} \text {. }\end{array}$ \\
\hline$\in(0,+\infty)$ & $\in(0,+\infty)$ & 0 & $\in(0,+\infty)$ & $\begin{array}{l}\text { Three roots which are dependent by quantity } \\
-0.25 q+0.5 \sqrt{\Delta_{1}} \pm \sqrt{\Delta_{4}} \text {. One double root and } \\
\text { one other which are real if }-0.25 q-0.5 \sqrt{\Delta_{1}}> \\
0 \text { and complex if }-0.25 q-0.5 \sqrt{\Delta_{1}}<0 \text {. }\end{array}$ \\
\hline$\in(0,+\infty)$ & $\in(0,+\infty)$ & $\in(0,+\infty)$ & $\in(-\infty, 0)$ & $\begin{array}{l}\text { Three complex roots and three other roots which } \\
\text { are dependent by quantity } \\
-0.25 q-0.5 \sqrt{\Delta_{1}} \pm \sqrt{\Delta_{3}} \text {. }\end{array}$ \\
\hline$\in(0,+\infty)$ & $\in(0,+\infty)$ & $\in(0,+\infty)$ & 0 & $\begin{array}{l}\text { One double root and one other which are real if } \\
-0.25 q+0.5 \sqrt{\Delta_{1}}>0 \text { and complex if } \\
\quad-0.25 q+0.5 \sqrt{\Delta_{1}}<0 \text {. } \\
\text { Three roots which are dependent by quantity } \\
-0.25 q-0.5 \sqrt{\Delta_{1}} \pm \sqrt{\Delta_{3}}\end{array}$ \\
\hline$\in(0,+\infty)$ & $\in(0,+\infty)$ & $\in(0,+\infty)$ & $\in(0,+\infty)$ & $\begin{array}{c}\text { Three roots which are dependent by quantity } \\
-0.25 q-0.5 \sqrt{\Delta_{1}} \pm \sqrt{\Delta_{3}} \text { and three other } \\
\text { which are dependent by quantity } \\
-0.25 q+0.5 \sqrt{\Delta_{1}} \pm \sqrt{\Delta_{4}}\end{array}$ \\
\hline
\end{tabular}

Since the radicals of equation (6) and consequently equation (1) can now be calculated, the sole problem is the existence of constraint (13). The necessary compliance of 
relation (13) negates the possibility of calculating the radicals of a random sextic polynomial $\mathrm{H}(\mathrm{x})$ with coefficients independent of each other. In this case, in order to bypass this problem, we consider the differences and deviations between the roots of a given polynomial equation $\mathrm{P}(\mathrm{x})$ with coefficients within a certain interval of values and a defined polynomial equation $\mathrm{Q}(\mathrm{x})$ with coefficients in the same interval and a dependent fixed term $\mathrm{t} / \mathrm{t}^{\prime}=\mathrm{f}(\mathrm{p}, \mathrm{q}, \mathrm{r}, \mathrm{s})$ and $\mathrm{t}^{\prime}=\mathrm{f}(\mathrm{p}, \mathrm{q}, \mathrm{r}, \mathrm{s})$ under constraint (13). The roots of $\mathrm{Q}(\mathrm{x})$ are calculated as defined in (16) (25). From the repetition and completion of the above procedure for $n$ pairs of equations $P$ and $\mathrm{Q}$, a sample of numerical values is compiled from which a mathematical model can be derived by regression analysis for the approximate calculation of the roots of the given sextic equation $\mathrm{P}(\mathrm{x})$, while there is no necessity of compliance with equation (13).

\subsection{Second part, regression analysis and mathematical model}

In the second step of the methodology, a mathematical model is created between the ratio of the roots to the ratio of the fixed terms for the pairs of the sextic polynomial equations under consideration. It is obvious that the more pairs of equations involved in the sample, the more reliable the result from the regression analysis. The basic model of the methodology refers to its ability to determine the roots of a random sextic polynomial equation $\mathrm{P}(\mathrm{x})$ with:

$$
\begin{gathered}
P(x)=y^{6}+p y^{4}+q y^{3}+r y^{2}+\text { sy }+ \text { t with roots } \rho_{1} \ldots \rho_{6} \\
Q(x)=y^{6}+p y^{4}+q y^{3}+r y^{2}+s y+t^{\prime} \text { with roots } \rho_{1}^{\prime} \ldots \rho_{6}^{\prime} \text { and } t^{\prime}=f(p, q, r, s)
\end{gathered}
$$

After the regression analysis, the roots and the fixed terms of the polynomial equations are correlated as follows:

$$
\frac{\rho}{\rho^{\prime}}=f\left(\frac{\mathrm{t}}{\mathrm{t}^{\prime}}\right) \Leftrightarrow \rho=\rho^{\prime} f\left(\frac{\mathrm{t}}{\mathrm{t}^{\prime}}\right)
$$

If $\rho$ are the roots of equation $\mathrm{P}(\mathrm{x})$ and $\rho^{\prime}$ are the roots of equation $\mathrm{Q}(\mathrm{x})$ which can be calculated due to the compliance with equation (13), $\mathrm{t}^{\prime}$ the dependent fixed term of $\mathrm{Q}(\mathrm{x})$ which is equal to that defined in equation (13), $\rho$ is the approximate root of the random sextic polynomial equation $P(x)$ and $t$ the fixed term of the given sextic equation $P(x)$, where $f$, is the function resulting from the regression analysis which calculates the ratio of the roots to the ratio of the fixed terms.

In the above model we consider that all the roots of sextic polynomials are complex. If they are real, then the imaginary part counts as zero. Then two separate regressions are performed, one for the real part of the roots and one for the imaginary part of the roots. This practice is applied because it is quite difficult to mathematically model, process and analyze regression in complex numbers to form a single mathematical model for the numerical correlation of parameters. Based on the above, relation (25) is written as:

$$
\begin{aligned}
& \frac{\operatorname{Re}(\rho)}{\operatorname{Re}\left(\rho^{\prime}\right)}=f_{\operatorname{Re}}\left(\frac{\mathrm{t}}{\mathrm{t}^{\prime}}\right) \Leftrightarrow \operatorname{Re}(\rho)=\operatorname{Re}\left(\rho^{\prime}\right) f_{\operatorname{Re}}\left(\frac{\mathrm{t}}{\mathrm{t}^{\prime}}\right) \\
& \frac{\operatorname{Im}(\rho)}{\operatorname{Im}\left(\rho^{\prime}\right)}=f_{\operatorname{Im}}\left(\frac{\mathrm{t}}{\mathrm{t}^{\prime}}\right) \Leftrightarrow \operatorname{Im}(\rho)=\operatorname{Im}\left(\rho^{\prime}\right) f_{\operatorname{Im}}\left(\frac{\mathrm{t}}{\mathrm{t}^{\prime}}\right)
\end{aligned}
$$

In order to come up with the final formula for calculating the approximate roots, this is the sum of (29a) and (29b). 


$$
\rho_{1} \ldots \rho_{6}=\operatorname{Re}(\rho)+\operatorname{Im}(\rho)=\operatorname{Re}\left(\rho^{\prime}\right) f_{\operatorname{Re}}\left(\frac{\mathrm{t}}{\mathrm{t}^{\prime}}\right)+\operatorname{Im}\left(\rho^{\prime}\right) f_{\operatorname{Im}}\left(\frac{\mathrm{t}}{\mathrm{t}^{\prime}}\right)
$$

For each root of the pair of equations $\mathrm{P}(\mathrm{x})$ and $\mathrm{Q}(\mathrm{x})$ two numerical values must be taken; one for the real part of the roots and one for the imaginary part of the roots; hence a total of four values in total per pair of $\mathrm{P}(\mathrm{x})$ and $\mathrm{Q}(\mathrm{x})$. For the six roots of a sextic equation, twelve values are obtained, so for two sextic equations $\mathrm{P}(\mathrm{x}), \mathrm{Q}(\mathrm{x})$ we get twenty-four values in total for the real and the imaginary part. The following diagram shows the steps for establishing this combined methodology which consists of algebraic procedures as well as the application of a statistical method.

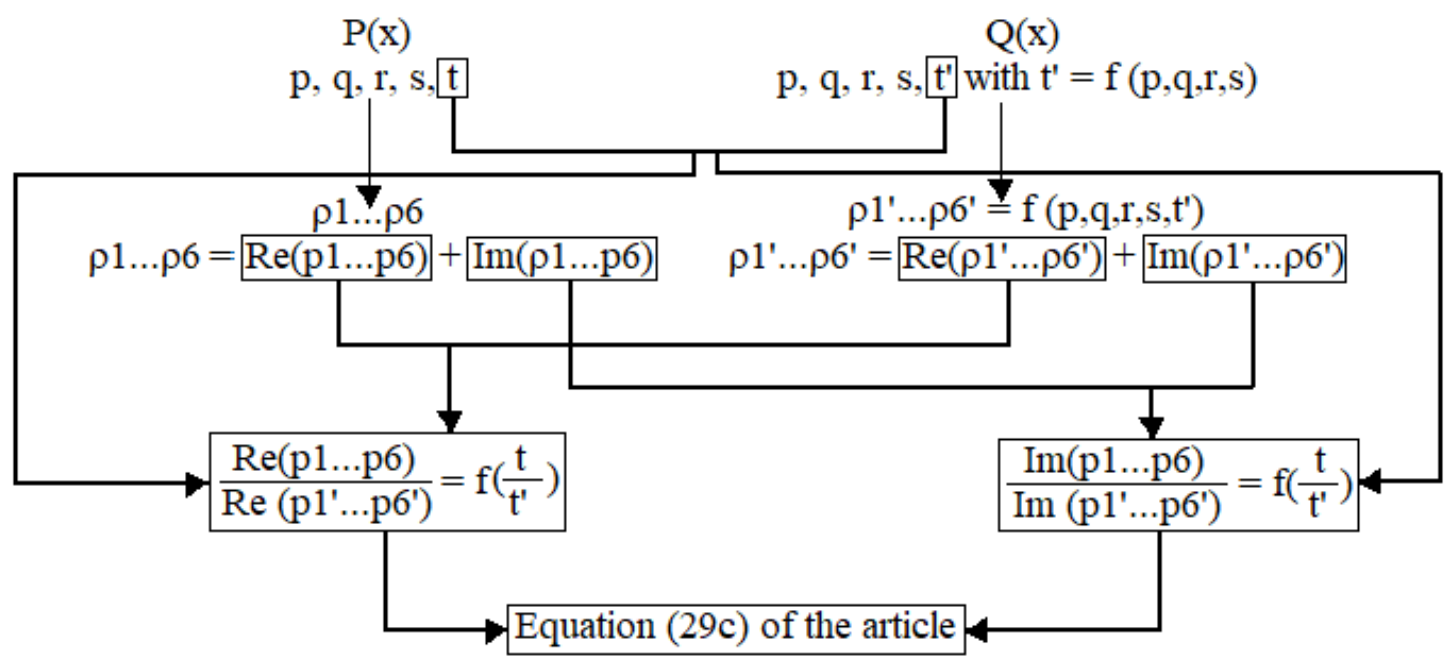

Figure 1. Schematic of methodological process for part 2.2.

\subsection{Sample creation}

Creating the necessary sample of equations to produce a reliable model is a difficult and complex process, since for a sextic equation with five coefficients such as in (6), a combination of a very large number of equations is required to be taken into account in the sample to cover the value range to which the coefficients of the polynomial equations belong. The number of different equations $\mathrm{P}(\mathrm{x})$ and $\mathrm{Q}(\mathrm{x})$ that must be taken into account in the sample in order for it to be representative depends mainly on the maximum number of different $\mathrm{N}$ numbers that each coefficient of the equation can take. The number $\mathrm{N}$ is determined by three parameters, the set of numbers to which the coefficients $\mathrm{P}(\mathrm{x})$ and $\mathrm{Q}(\mathrm{x})$ belong, the value range of the coefficients to be taken into account and finally the step $\mathrm{S}$ by which the coefficients will change within the specified value range. The above-mentioned parameters form the number $\mathrm{N}$.

For instance, a bigger sample of different equations will be needed for the equation $\mathrm{x}^{6}+\mathrm{px}^{4}+\mathrm{qx}^{3}+\mathrm{rx}^{2}+\mathrm{sx}+\mathrm{t}$ where $\{\mathrm{p}, \mathrm{q}, \mathrm{r}, \mathrm{s}, \mathrm{t}\} \in \mathrm{R}$ within the interval $[-10,10]$ with $\mathrm{S}$ equal to 0.1 than for the equation $x^{6}+r^{2}+s x+t$ where $\{r, s, t\} \in Z$ within the interval [$2,8]$ with $S$ equal to 1 . It is obvious that the higher the above parameters, the higher the number of different equations to be taken into account. Suppose the coefficient $p$, where $p \in$ $[a, b] \forall\{a, b\} \in R / \beta>\alpha$ and $S>0$. The number $N+1$ with $N \in N$ of the numbers belonging within $[a, b]$ and have the form of $a, a+S, a+2 S \ldots a+N S$ and are less than or equal to $b$, are expressed as a $+\mathrm{NS} \leq \mathrm{b}$. It is concluded that the number $\mathrm{N}$ of the numbers is equal to:

$$
\mathrm{N}=\left[\frac{\mathrm{b}-\mathrm{a}}{\mathrm{S}}\right]+1
$$


If $\mathrm{N}$ occurs to be a non-natural number, for instance a decimal number, then rounding is performed. The number $\mathrm{N}_{\mathrm{EQ}}$ of the different polynomial equations $\mathrm{P}(\mathrm{x})$ and $\mathrm{Q}(\mathrm{x})$ based on the number $\mathrm{N}$, number $\mathrm{N}_{\mathrm{C}}$ and the coefficients taken into account and are included in the sample is equal to:

$$
\mathrm{N}_{\mathrm{EQ}}=\mathrm{N}^{\mathrm{N}_{\mathrm{C}}}
$$

Table 1. Number $\mathrm{N}_{\mathrm{EQ}}$ of the different polynomial equations based on the number $\mathrm{N}_{\mathrm{C}}$ the coefficients taken into account and the interval they belong, where $\{\mathrm{p}, \mathrm{q}, \mathrm{r}, \mathrm{s}, \mathrm{t}\} \in \mathrm{N}$ and $\mathrm{S}=1$.

\begin{tabular}{|c|c|c|c|c|c|c|}
\hline Interval & $\mathrm{N}$ & $\begin{array}{c}\mathrm{p} \\
\mathrm{N}_{\mathrm{C}}=1\end{array}$ & $\begin{array}{c}\mathrm{p}, \mathrm{q} \\
\mathrm{N}_{\mathrm{C}}=2\end{array}$ & $\begin{array}{c}\mathrm{p}, \mathrm{q}, \mathrm{r} \\
\mathrm{N}_{\mathrm{C}}=3\end{array}$ & $\begin{array}{c}\mathrm{p}, \mathrm{q}, \mathrm{r}, \mathrm{s} \\
\mathrm{N}_{\mathrm{C}}=4\end{array}$ & $\begin{array}{c}\mathrm{p}, \mathrm{q}, \mathrm{r}, \mathrm{s}, \mathrm{t} \\
\mathrm{N}_{\mathrm{C}}=5\end{array}$ \\
\hline$[1,2]$ & 2 & 2 & 4 & 8 & 16 & 32 \\
{$[1,3]$} & 3 & 3 & 9 & 27 & 81 & 243 \\
{$[1,6]$} & 6 & 6 & 36 & 216 & 1296 & 7776 \\
{$[1,10]$} & 10 & 10 & 100 & 1000 & 10000 & 100000 \\
{$[1,20]$} & 20 & 20 & 400 & 8000 & 160000 & 3200000 \\
\hline
\end{tabular}

In the next table the same interval with a different step $S$ and $\{p, q, r, s, t\} \in R$ is portrayed.

Table 2. Number $\mathrm{N}_{\mathrm{EQ}}$ of the different polynomial equations based on the number $\mathrm{N}_{\mathrm{C}}$ the coefficients taken into account and the interval they belong, where $\{p, q, r, s, t\} \in R$ and different step $\mathrm{S}$.

\begin{tabular}{|c|c|c|c|c|c|c|c|}
\hline Interval & $\mathrm{S}$ & $\mathrm{N}$ & $\begin{array}{c}\mathrm{p} \\
\mathrm{N}_{\mathrm{C}}=1\end{array}$ & $\begin{array}{c}\mathrm{p}, \mathrm{q} \\
\mathrm{N}_{\mathrm{C}}=2\end{array}$ & $\begin{array}{c}\mathrm{p}, \mathrm{q}, \mathrm{r} \\
\mathrm{N}_{\mathrm{C}}=3\end{array}$ & $\begin{array}{c}\mathrm{p}, \mathrm{q}, \mathrm{r}, \mathrm{s} \\
\mathrm{N}_{\mathrm{C}}=4\end{array}$ & $\begin{array}{c}\mathrm{p}, \mathrm{q}, \mathrm{r}, \mathrm{s}, \mathrm{t} \\
\mathrm{N}_{\mathrm{C}}=5\end{array}$ \\
\hline$[1,2]$ & 0.01 & 101 & 101 & 10201 & 1030301 & 104060401 & 10510100501 \\
{$[1,3]$} & 0.05 & 41 & 41 & 1681 & 68921 & 2825761 & 115856201 \\
{$[1,6]$} & 0.1 & 51 & 51 & 2601 & 132651 & 6765201 & 345025251 \\
{$[1,10]$} & 0.2 & 46 & 46 & 2116 & 97336 & 4477456 & 205962976 \\
{$[1,20]$} & 1 & 20 & 20 & 400 & 8000 & 160000 & 3200000 \\
\hline
\end{tabular}

Table 3. Number $\mathrm{N}_{\mathrm{EQ}}$ of the different polynomial equations based on the number $\mathrm{N}_{\mathrm{C}}$ the coefficients taken into account and the interval they belong, where $\{\mathrm{p}, \mathrm{q}, \mathrm{r}, \mathrm{s}, \mathrm{t}\} \in \mathrm{R}$ and different step $\mathrm{S}$.

\begin{tabular}{|c|c|c|c|c|c|c|c|}
\hline Interval & $\mathrm{S}$ & $\mathrm{N}$ & $\begin{array}{c}\mathrm{p} \\
\mathrm{N}_{\mathrm{C}}=1\end{array}$ & $\begin{array}{c}\mathrm{p}, \mathrm{q} \\
\mathrm{N}_{\mathrm{C}}=2\end{array}$ & $\begin{array}{c}\mathrm{p}, \mathrm{q}, \mathrm{r} \\
\mathrm{N}_{\mathrm{C}}=3\end{array}$ & $\begin{array}{c}\mathrm{p}, \mathrm{q}, \mathrm{r}, \mathrm{s} \\
\mathrm{N}_{\mathrm{C}}=4\end{array}$ & $\begin{array}{c}\mathrm{p}, \mathrm{q}, \mathrm{r}, \mathrm{s}, \mathrm{t} \\
\mathrm{N}_{\mathrm{C}}=5\end{array}$ \\
\hline$[-10,-1]$ & 0.1 & 91 & 91 & 8281 & 753571 & 68574961 & 6240321451 \\
{$[-7,2]$} & 0.2 & 46 & 46 & 2116 & 97336 & 4477456 & 205962976 \\
{$[-5,2]$} & 0.3 & 24 & 24 & 576 & 13824 & 331776 & 7962624 \\
{$[-2,10]$} & 0.4 & 31 & 31 & 961 & 29791 & 923521 & 28629151 \\
{$[-1,12]$} & 0.5 & 27 & 27 & 729 & 19683 & 531441 & 14348907 \\
\hline
\end{tabular}

Tables 1 to 3 are an example of the volume of data operations and combinations that must be processed to achieve a reliable mathematical model. In this article, mathematical models will be listed, only for a limited range of values and step.

\section{Results, applications and examples}

\subsection{Investigation of equation $x^{6}+r x^{2}+s x+t=0$ with $S=1$ within $[1,2]$}

Starting with the depressed sextic equation $\mathrm{P}(\mathrm{x})=\mathrm{x}^{6}+\mathrm{rx}^{2}+\mathrm{sx}+\mathrm{t}=0$. The characteristics of the equation for the modelling to be performed are that, $\mathrm{pq}=0$ and $\{\mathrm{r}, \mathrm{s}, \mathrm{t}\}$ $\in[1,2]$ with step $S=1$. Based on the above $N=2, N_{C}=3$ and $N_{E Q}=8$. Therefore, eight different combinations of equations $\mathrm{P}$ and $\mathrm{Q}$ must be made from which 96 different roots will 
result. Below the modelling for only one of the six roots is displayed. From the processing of the numerical data of Table 4 with regression analysis, the following mathematical correlation model and the corresponding correlation coefficient emerge.

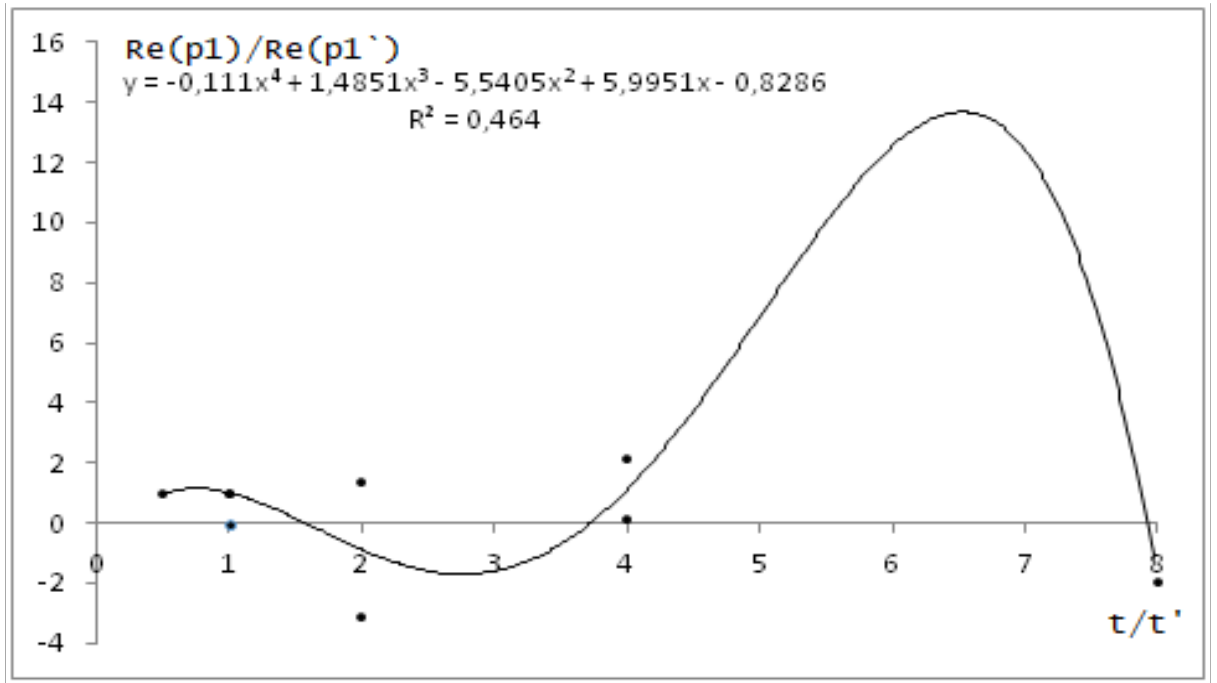

Figure 2. Numerical correlation between $\operatorname{Re}\left(\mathrm{p}_{1}\right) / \operatorname{Re}\left(\mathrm{p}_{1}{ }^{\prime}\right)$ to $\mathrm{t} / \mathrm{t}^{\prime}$ ratio.

$$
\frac{\operatorname{Re}\left(\mathrm{p}_{1}\right)}{\operatorname{Re}\left(\mathrm{p}_{1}{ }^{\prime}\right)}=-0.111\left(\frac{\mathrm{t}}{\mathrm{t}^{\prime}}\right)^{4}+1.4851\left(\frac{\mathrm{t}}{\mathrm{t}^{\prime}}\right)^{3}-5.5405\left(\frac{\mathrm{t}}{\mathrm{t}^{\prime}}\right)^{2}+5.9951\left(\frac{\mathrm{t}}{\mathrm{t}^{\prime}}\right)-0.8286
$$

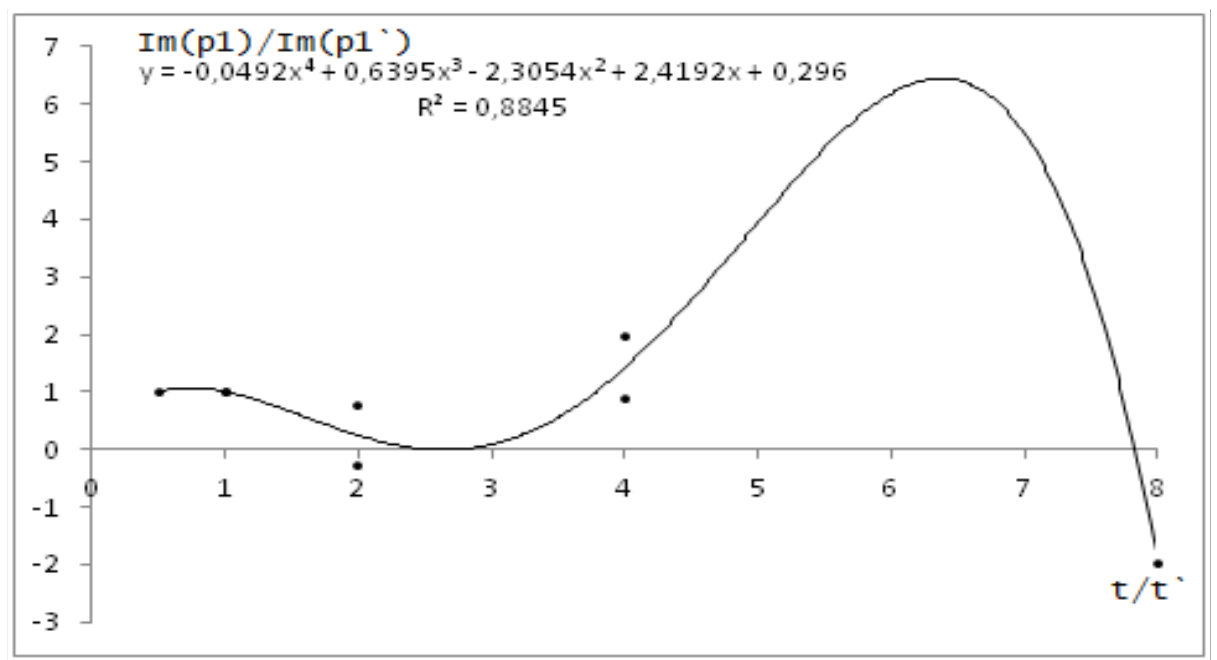

Figure 3. Numerical correlation between $\operatorname{Im}\left(\mathrm{p}_{1}\right) / \operatorname{Im}\left(\mathrm{p}_{1}{ }^{\prime}\right)$ to $\mathrm{t} / \mathrm{t}^{\prime}$ ratio.

$$
\frac{\operatorname{Im}\left(\mathrm{p}_{1}\right)}{\operatorname{Im}\left(\mathrm{p}_{1}{ }^{\prime}\right)}=-0.0492\left(\frac{\mathrm{t}}{\mathrm{t}^{\prime}}\right)^{4}+0.6395\left(\frac{\mathrm{t}}{\mathrm{t}^{\prime}}\right)^{3}-2.3054\left(\frac{\mathrm{t}}{\mathrm{t}^{\prime}}\right)^{2}+2.4192\left(\frac{\mathrm{t}}{\mathrm{t}^{\prime}}\right)-0.296
$$

Substituting (32) and (33) into formulas (29a) - (29c), we arrive at the approximate solution of one of the six roots of the equation. In the above model the difference of the correlation coefficient between the model for the real part $\operatorname{Re}\left(\mathrm{p}_{1}\right)$ and the imaginary part $\operatorname{Im}\left(\mathrm{p}_{1}\right)$ of the root is interesting. A quartic polynomial has achieved an almost $40 \%$ increase in the correlation coefficient. The correlation coefficient of the regression analysis for the real part $\operatorname{Re}\left(\mathrm{p}_{1}\right)$ is $\mathrm{c}=0.68$ and for the imaginary $\operatorname{part} \operatorname{Im}\left(\mathrm{p}_{1}\right)$ is $\mathrm{c}=0.94$. 
Table 4. All possible combinations of equations $\mathrm{P}(\mathrm{x}), \mathrm{Q}(\mathrm{x})$, their roots and the necessary data for the mathematical modelling of application 3.1.

\begin{tabular}{|c|c|c|c|c|c|c|c|c|c|}
\hline \multirow{3}{*}{ 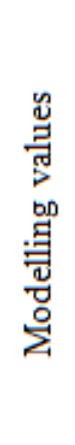 } & $\begin{array}{c}\text { 임 } \\
\vdots \\
\vdots\end{array}$ & $\stackrel{\text { ڤ. }}{-}$ & \begin{tabular}{l}
$\infty$ \\
$\infty$ \\
$\infty$ \\
$\curvearrowright$ \\
\hdashline \\
\end{tabular} & 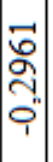 & $\begin{array}{c}\infty \\
\infty \\
\infty \\
0^{\prime}\end{array}$ & -1 & $\begin{array}{l}0 \\
0 \\
0 \\
0 \\
0\end{array}$ & \begin{tabular}{|c|}
2 \\
0 \\
0 \\
0 \\
- \\
$-i$
\end{tabular} & \\
\hline & 仓) & $\begin{array}{l}n \\
\hat{2} \\
0 \\
= \\
0 .\end{array}$ & 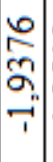 & $\mid \begin{array}{c}9 \\
\vdots \\
n \\
\cdots \\
- \\
-\end{array}$ & $\begin{array}{l}\stackrel{ \pm}{2} \\
\stackrel{2}{2} \\
\text { ה. }\end{array}$ & - & $\begin{array}{l}\hat{n} \\
\hat{y} \\
\\
r\end{array}$ & 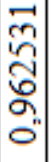 & \\
\hline & $+1 \%$ & + & $\infty$ & $N \mid$ & + & -1 & $N$ & "n & -1 \\
\hline \multirow{5}{*}{ 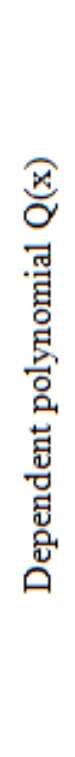 } & 萼 & 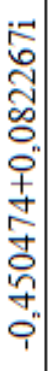 & 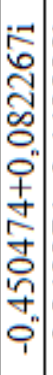 & 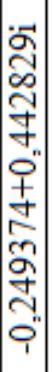 & 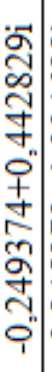 & 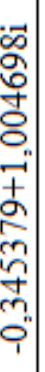 & 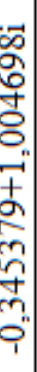 & 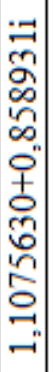 & 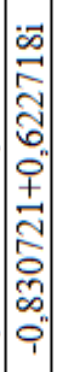 \\
\hline & 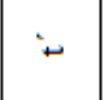 & त̂ & ڤn. & 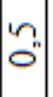 & "n. & -1 & -1 & $N$ & $\sim$ \\
\hline & 肴 & -1 & -1 & -1 & -1 & v & $N$ & $\sim$ & N \\
\hline & 次 & -1 & -1 & $N \mid$ & $\mathrm{N}$ & -1 & -1 & $\sim$ & $N$ \\
\hline & ${ }^{\circ} x_{x}$ & -1 & -1 & -1 & -1 & -1 & -1 & -1 & - \\
\hline \multirow{5}{*}{ 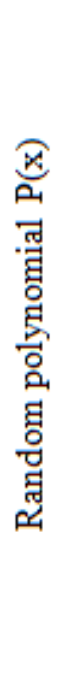 } & 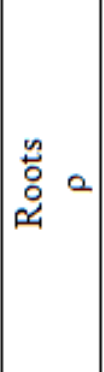 & 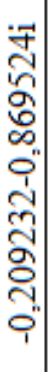 & 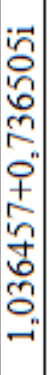 & 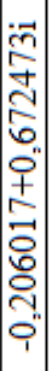 & 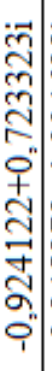 & 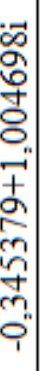 & 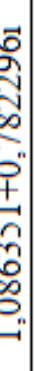 & 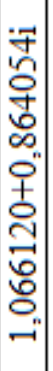 & 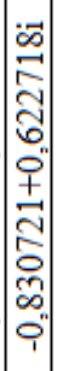 \\
\hline & $\leftarrow$ & - & $N$ & -1 & $N$ & -1 & $N$ & -1 & $N$ \\
\hline & 炭 & - & -1 & -1 & -1 & N & $N$ & $N$ & $N$ \\
\hline & 出 & -1 & -1 & $N$ & $N$ & -1 & -1 & $N \mid$ & $N$ \\
\hline & ${ }_{x}^{\circ}$ & & & & & - & 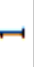 & -1 & 17 \\
\hline
\end{tabular}




\subsection{Investigation of equation $\mathrm{x}^{6}+\mathrm{px}^{4}+\mathrm{qx^{3 }}+\mathrm{rx}^{2}+\mathrm{sx}+\mathrm{t}=\mathbf{0}$ with $\mathrm{S}=1$ within $[1,2]$}

Assuming equation $\mathrm{P}(\mathrm{x})=\mathrm{x}^{6}+\mathrm{px}^{4}+\mathrm{qx}^{3}+\mathrm{rx}^{2}+\mathrm{sx}+\mathrm{t}=0$; An equation identical with equation (6) without quintic term, where $\{p, q, r, s, t\} \in[1,2]$ and $S=1$, so that $\mathrm{N}=2, \mathrm{~N}_{\mathrm{C}}=5$ and $\mathrm{N}_{\mathrm{EQ}}=32$. Thirty two different combinations with the coefficients of $\mathrm{P}(\mathrm{x})$ and $\mathrm{Q}(\mathrm{x})$ are required with a range of value of 1 and 2 .

Table 5. All possible combinations of equations $\mathrm{P}, \mathrm{Q}$ based on the above requirements.

\begin{tabular}{|c|c|c|c|c|c|c|c|c|c|c|c|c|c|c|c|}
\hline \multicolumn{6}{|c|}{ Random polynomial $\mathrm{P}(\mathrm{x})$} & \multicolumn{2}{|c|}{ Roots of $\mathrm{P}(\mathrm{x})$} & \multicolumn{6}{|c|}{ Dependent polynomial Q(x) } & \multicolumn{2}{|c|}{ Roots of Q(x) } \\
\hline$x^{6}$ & $\mathrm{px}^{4}$ & $q x^{3}$ & $\mathrm{rx}^{2}$ & sx & $\mathrm{t}$ & $\operatorname{Re}\left(\rho_{1}\right)$ & $\operatorname{Im}\left(\rho_{1}\right)$ & $x^{6}$ & $\mathrm{px}^{4}$ & $q x^{3}$ & $\mathrm{rx}^{2}$ & $\mathrm{sx}$ & $\mathrm{t}^{\prime}$ & $\operatorname{Re}\left(\rho_{1}^{\prime}\right)$ & $\operatorname{Im}\left(\rho_{1}^{\prime}\right)$ \\
\hline 1 & 1 & 1 & 1 & 1 & 1 & 0,7271 & 0,9341 & 1 & 1 & 1 & 1 & 1 & 0,167 & 0,6677 & 1,0138 \\
\hline 1 & 1 & 1 & 1 & 1 & 2 & 0,816 & 0,8944 & 1 & 1 & 1 & 1 & 1 & 0,167 & 0,6677 & 1,0138 \\
\hline 1 & 1 & 1 & 1 & 2 & 1 & 0,8317 & 0,9659 & 1 & 1 & 1 & 1 & 2 & $-0,33$ & 0,7622 & 1,0359 \\
\hline 1 & 1 & 1 & 1 & 2 & 2 & 0,8907 & 0,9403 & 1 & 1 & 1 & 1 & 2 & $-0,33$ & 0,7622 & 1,0359 \\
\hline 1 & 1 & 1 & 2 & 1 & 1 & 0,8808 & 1,055 & 1 & 1 & 1 & 2 & 1 & 0,214 & 0,776 & 1,1021 \\
\hline 1 & 1 & 1 & 2 & 1 & 2 & 0,8498 & 1,0082 & 1 & 1 & 1 & 2 & 1 & 0,214 & 0,776 & 1,1021 \\
\hline 1 & 1 & 1 & 2 & 2 & 1 & 0,8811 & 1,0596 & 1 & 1 & 1 & 2 & 2 & 0 & 0 & 0 \\
\hline 1 & 1 & 1 & 2 & 2 & 2 & 0,9211 & 1,0302 & 1 & 1 & 1 & 2 & 2 & 0 & 0 & 0 \\
\hline 1 & 1 & 2 & 1 & 1 & 1 & 0,6624 & 1,1472 & 1 & 1 & 2 & 1 & 1 & 1 & 0,6624 & 1,172 \\
\hline 1 & 1 & 2 & 1 & 1 & 2 & $-0,9319$ & 0,429 & 1 & 1 & 2 & 1 & 1 & 1 & 0,6624 & 1,172 \\
\hline 1 & 1 & 2 & 1 & 2 & 1 & 0,7718 & 1,1151 & 1 & 1 & 2 & 1 & 2 & 0,5 & 0,758 & 1,1468 \\
\hline 1 & 1 & 2 & 1 & 2 & 2 & 0,8167 & 1,062 & 1 & 1 & 2 & 1 & 2 & 0,5 & 0,758 & 1,1468 \\
\hline 1 & 1 & 2 & 2 & 1 & 1 & 0,7816 & 1,2182 & 1 & 1 & 2 & 2 & 1 & 1 & 0,7816 & 1,2182 \\
\hline 1 & 1 & 2 & 2 & 1 & 2 & 0,7966 & 1,162 & 1 & 1 & 2 & 2 & 1 & 1 & 0,7816 & 1,2182 \\
\hline 1 & 1 & 2 & 2 & 2 & 1 & 0,8499 & 1,1955 & 1 & 1 & 2 & 2 & 2 & 0,786 & 0,8463 & 1,2044 \\
\hline 1 & 1 & 2 & 2 & 2 & 2 & 0,8734 & 1,1556 & 1 & 1 & 2 & 2 & 2 & 0,786 & 0,8463 & 1,2044 \\
\hline 1 & 2 & 1 & 1 & 1 & 1 & - & - & 1 & 2 & 1 & 1 & 1 & - & - & - \\
\hline 1 & 2 & 1 & 1 & 1 & 2 & - & - & 1 & 2 & 1 & 1 & 1 & - & - & - \\
\hline 1 & 2 & 1 & 1 & 2 & 1 & - & - & 1 & 2 & 1 & 1 & 2 & - & - & - \\
\hline 1 & 2 & 1 & 1 & 2 & 2 & - & - & 1 & 2 & 1 & 1 & 2 & - & - & - \\
\hline 1 & 2 & 1 & 2 & 1 & 1 & 0,5474 & 1,1209 & 1 & 2 & 1 & 2 & 1 & 0,25 & 0,5544 & 1,2099 \\
\hline 1 & 2 & 1 & 2 & 1 & 2 & 0,6316 & 1,0057 & 1 & 2 & 1 & 2 & 1 & 0,25 & 0,5544 & 1,2099 \\
\hline 1 & 2 & 1 & 2 & 2 & 1 & 0,6829 & 1,1066 & 1 & 2 & 1 & 2 & 2 & $-0,13$ & 0,6524 & 1,1873 \\
\hline 1 & 2 & 1 & 2 & 2 & 2 & 0,7381 & 1,052 & 1 & 2 & 1 & 2 & 2 & $-0,13$ & 0,6524 & 1,1873 \\
\hline 1 & 2 & 2 & 1 & 1 & 1 & - & - & 1 & 2 & 2 & 1 & 1 & - & - & - \\
\hline 1 & 2 & 2 & 1 & 1 & 2 & - & - & 1 & 2 & 2 & 1 & 1 & - & - & - \\
\hline 1 & 2 & 2 & 1 & 2 & 1 & - & - & 1 & 2 & 2 & 1 & 2 & - & - & - \\
\hline 1 & 2 & 2 & 1 & 2 & 2 & - & - & 1 & 2 & 2 & 1 & 2 & - & - & - \\
\hline 1 & 2 & 2 & 2 & 1 & 1 & 0,5613 & 1,3797 & 1 & 2 & 2 & 2 & 1 & 1,125 & 0,5557 & 1,3737 \\
\hline 1 & 2 & 2 & 2 & 1 & 2 & $-0,809$ & 0,5878 & 1 & 2 & 2 & 2 & 1 & 1,125 & 0,5557 & 1,3737 \\
\hline 1 & 2 & 2 & 2 & 2 & 1 & 0,6248 & 1,3002 & 1 & 2 & 2 & 2 & 2 & 0,75 & 0,6286 & 1,3169 \\
\hline 1 & 2 & 2 & 2 & 2 & 2 & 0,6251 & 1,2142 & 1 & 2 & 2 & 2 & 2 & 0,75 & 0,6286 & 1,3169 \\
\hline
\end{tabular}

Of the 32 equations, only 27 are considered for modelling because the fixed term $t^{\prime}$ of $\mathrm{Q}(\mathrm{x})$ could not be calculated due to the constraint $\mathrm{p}^{2}-4 \mathrm{r} \neq 0$ as well as the ratios $\operatorname{Re}\left(\rho_{1}\right) / \operatorname{Re}\left(\rho_{1}{ }^{\prime}\right)$ and $\operatorname{Im}\left(\rho_{1}\right) / \operatorname{Im}\left(\rho_{1}{ }^{\prime}\right)$. Based on the values of Table 5 , the regression analysis shows the following optimal correlation model.

$$
\begin{gathered}
\frac{\operatorname{Re}\left(\mathrm{p}_{1}\right)}{\operatorname{Re}\left(\mathrm{p}_{1}{ }^{\prime}\right)}=\frac{1.093\left(\frac{\mathrm{t}}{\mathrm{t}^{\prime}}\right)^{3}+3.198\left(\frac{\mathrm{t}}{\mathrm{t}^{\prime}}\right)^{2}-22.63\left(\frac{\mathrm{t}}{\mathrm{t}^{\prime}}\right)+23.81}{\left(\frac{\mathrm{t}}{\mathrm{t}^{\prime}}\right)^{3}+2.893\left(\frac{\mathrm{t}}{\mathrm{t}^{\prime}}\right)^{2}-20.53\left(\frac{\mathrm{t}}{\mathrm{t}^{\prime}}\right)+21.85}, \mathrm{R}^{2}=0.65 \\
\frac{\operatorname{Im}\left(\mathrm{p}_{1}\right)}{\operatorname{Im}\left(\mathrm{p}_{1}{ }^{\prime}\right)}=-0.6292 \exp \left(-\left(\frac{\frac{\mathrm{t}}{\mathrm{t}^{\prime}}-1.839}{0.147}\right)^{2}\right)+0.9644 \exp \left(-\left(\frac{\frac{\mathrm{t}}{\mathrm{t}^{\prime}}-2.162}{42.5}\right)\right), \mathrm{R}^{2}=0.55
\end{gathered}
$$




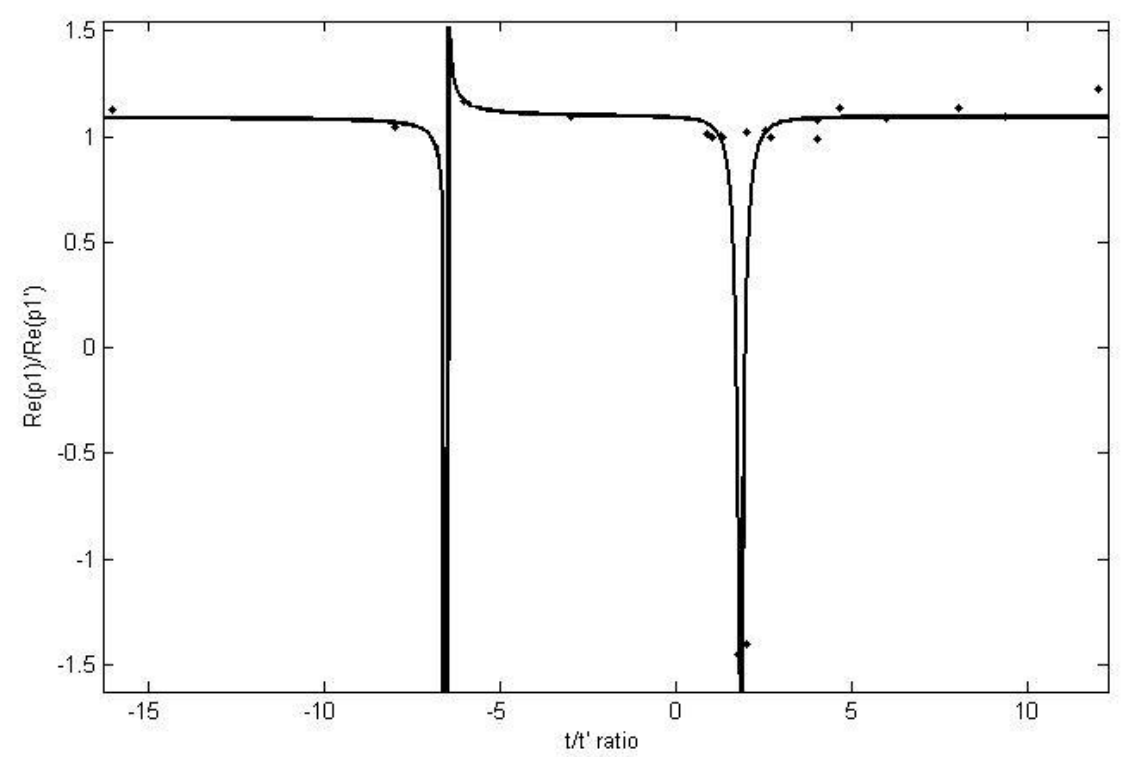

Figure 4. Numerical correlation between $\operatorname{Re}\left(\mathrm{p}_{1}\right) / \operatorname{Re}\left(\mathrm{p}_{1}{ }^{\prime}\right)$ to $\mathrm{t} / \mathrm{t}^{\prime}$ ratio.

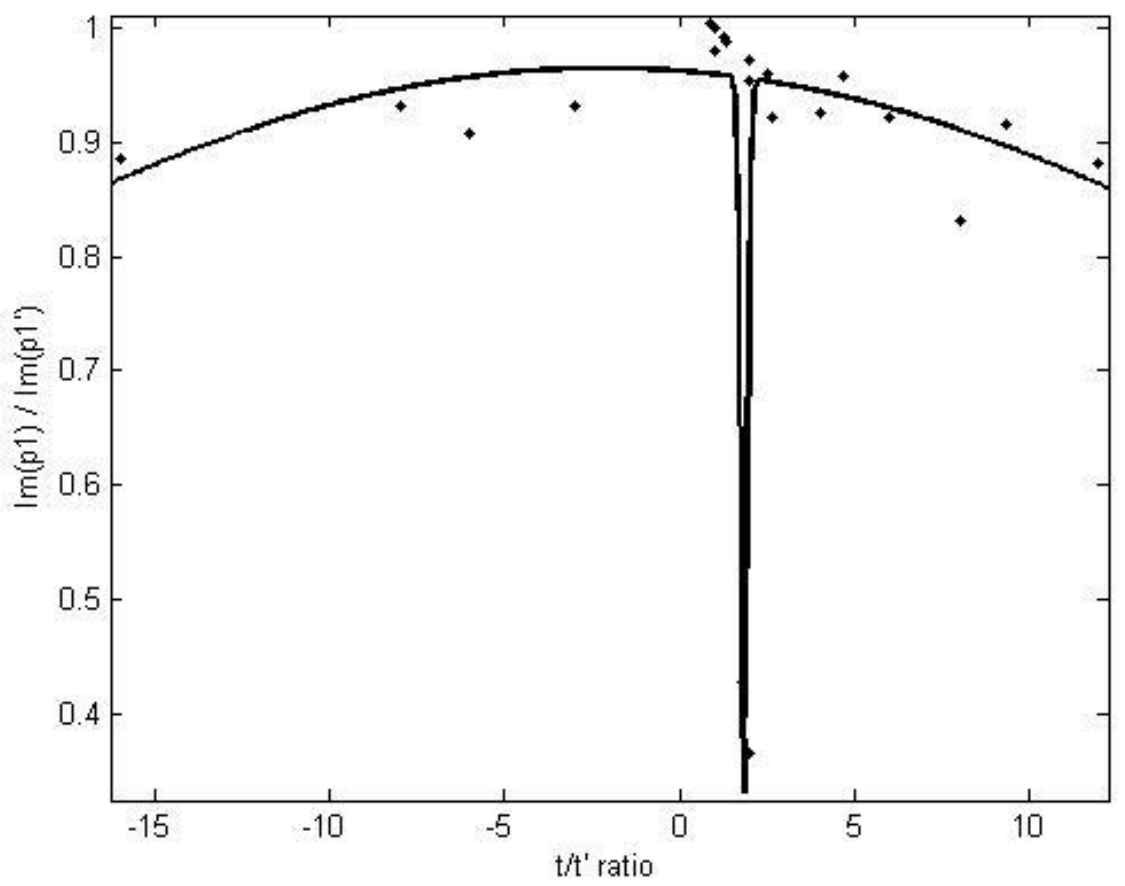

Figure 5. Numerical correlation between $\operatorname{Im}\left(\mathrm{p}_{1}\right) / \operatorname{Im}\left(\mathrm{p}_{1}{ }^{\prime}\right)$ to $\mathrm{t} / \mathrm{t}^{\prime}$ ratio.

From equation (34) for the real part of the root $\operatorname{Re}\left(\mathrm{p}_{1}\right)$, the correlation coefficient is $\mathrm{c}$ $=0.81$ whereas for the imaginary part of the root $\operatorname{Im}\left(\mathrm{p}_{1}\right)$ in equation (34) the correlation coefficient is $\mathrm{c}=0.74$.

\subsection{Investigation of equation $\mathrm{x}^{6}+\mathrm{rx}^{2}+\mathrm{sx}+\mathrm{t}=0$ with $\mathrm{S}=0.5$ within $[1,2]$}

Assuming the depressed sextic equation $\mathrm{P}(\mathrm{x})=\mathrm{x}^{6}+\mathrm{rx}^{2}+\mathrm{sx}+\mathrm{t}=0$, where $\mathrm{pq}=0$ and $\{\mathrm{r}, \mathrm{s}, \mathrm{t}\} \in[1,2]$ and $\mathrm{S}=0.5$. Based on the above $\mathrm{N}=3, \mathrm{~N}_{\mathrm{C}}=3$ and $\mathrm{N}_{\mathrm{EQ}}=27$. Hence, 27 different combinations of equations $\mathrm{P}(\mathrm{x})$ and $\mathrm{Q}(\mathrm{x})$ with 364 roots must be done. Below the modelling for only one of the six roots is displayed. 
Table 6. All possible combinations of equations $\mathrm{P}, \mathrm{Q}$ based on the above requirements.

\begin{tabular}{|cccc|c|c|cccc|c|c|}
\hline \multicolumn{3}{|c|}{ Random pol. P(x) } & \multicolumn{2}{c|}{ Roots of $\mathrm{P}(\mathrm{x})$} & \multicolumn{3}{c|}{ Dependent pol. Q(x) } & \multicolumn{2}{c|}{ Roots of $\mathrm{Q}(\mathrm{x})$} \\
\hline $\mathrm{x}^{6}$ & $\mathrm{rx}$ & $\mathrm{sx}$ & $\mathrm{t}$ & $\mathrm{Re}\left(\rho_{1}\right)$ & $\mathrm{Im}\left(\rho_{1}\right)$ & $\mathrm{x}^{6}$ & $\mathrm{rx}{ }^{2}$ & $\mathrm{sx}$ & $\mathrm{t} '$ & $\mathrm{Re}\left(\rho_{1}{ }^{\prime}\right)$ & $\mathrm{Im}\left(\rho_{1}{ }^{\prime}\right)$ \\
\hline 1 & 1 & 1 & 1 & 0,9693 & 0,731 & 1 & 1 & 1 & 0,25 & 0,903 & 0,7376 \\
1 & 1 & 1 & 1,5 & 1,0053 & 0,7328 & 1 & 1 & 1 & 0,25 & 0,903 & 0,7376 \\
1 & 1 & 1 & 2 & 1,0365 & 0,7365 & 1 & 1 & 1 & 0,25 & 0,903 & 0,7376 \\
1 & 1 & 1,5 & 1 & 1,0045 & 0,7574 & 1 & 1 & 1,5 & 0,563 & 0,9743 & 0,759 \\
1 & 1 & 1,5 & 1,5 & 1,0352 & 0,7583 & 1 & 1 & 1,5 & 0,563 & 0,9743 & 0,759 \\
1 & 1 & 1,5 & 2 & 1,0623 & 0,7608 & 1 & 1 & 1,5 & 0,563 & 0,9743 & 0,759 \\
1 & 1 & 2 & 1 & 1,0357 & 0,7802 & 1 & 1 & 2 & 1 & 1,0357 & 0,7802 \\
1 & 1 & 2 & 1,5 & 1,0623 & 0,7805 & 1 & 1 & 2 & 1 & 1,0357 & 0,7802 \\
1 & 1 & 2 & 2 & 1,0864 & 0,7823 & 1 & 1 & 2 & 1 & 1,0357 & 0,7802 \\
1 & 1,5 & 1 & 1 & 0,9863 & 0,784 & 1 & 1,5 & 1 & 0,167 & 0,9252 & 0,7986 \\
1 & 1,5 & 1 & 1,5 & 1,0181 & 0,7818 & 1 & 1,5 & 1 & 0,167 & 0,9252 & 0,7986 \\
1 & 1,5 & 1 & 2 & 1,0464 & 0,7821 & 1 & 1,5 & 1 & 0,167 & 0,9252 & 0,7986 \\
1 & 1,5 & 1,5 & 1 & 1,0203 & 0,805 & 1 & 1,5 & 1,5 & 0,375 & 0,9824 & 0,8118 \\
1 & 1,5 & 1,5 & 1,5 & 1,0476 & 0,803 & 1 & 1,5 & 1,5 & 0,375 & 0,9824 & 0,8118 \\
1 & 1,5 & 1,5 & 2 & 1,0724 & 0,8029 & 1 & 1,5 & 1,5 & 0,375 & 0,9824 & 0,8118 \\
1 & 1,5 & 2 & 1 & 1,0503 & 0,8236 & 1 & 1,5 & 2 & 0,667 & 1,0333 & 0,826 \\
1 & 1,5 & 2 & 1,5 & 1,0742 & 0,8219 & 1 & 1,5 & 2 & 0,667 & 1,0333 & 0,826 \\
1 & 1,5 & 2 & 2 & 1,0963 & 0,8216 & 1 & 1,5 & 2 & 0,667 & 1,0333 & 0,826 \\
1 & 2 & 1 & 1 & 1,0054 & 0,8323 & 1 & 2 & 1 & 0,125 & 0,9528 & 0,8505 \\
1 & 2 & 1 & 1,5 & 1,0331 & 0,8275 & 1 & 2 & 1 & 0,125 & 0,9528 & 0,8505 \\
1 & 2 & 1 & 2 & 1,0584 & 0,8252 & 1 & 2 & 1 & 0,125 & 0,9528 & 0,8505 \\
1 & 2 & 1,5 & 1 & 1,0376 & 0,8489 & 1 & 2 & 1,5 & 0,281 & 1,0003 & 0,8594 \\
1 & 2 & 1,5 & 1,5 & 1,0616 & 0,8449 & 1 & 2 & 1,5 & 0,281 & 1,0003 & 0,8594 \\
1 & 2 & 1,5 & 2 & 1,0841 & 0,8429 & 1 & 2 & 1,5 & 0,281 & 1,0003 & 0,8594 \\
1 & 2 & 2 & 1 & 1,0661 & 0,8641 & 1 & 2 & 2 & 0,5 & 1,0435 & 0,863 \\
1 & 2 & 2 & 1,5 & 1,0875 & 0,8608 & 1 & 2 & 2 & 0,5 & 1,0435 & 0,863 \\
1 & 2 & 2 & 2 & 1,1076 & 0,8589 & 1 & 2 & 2 & 0,5 & 1,0435 & 0,863 \\
\hline
\end{tabular}

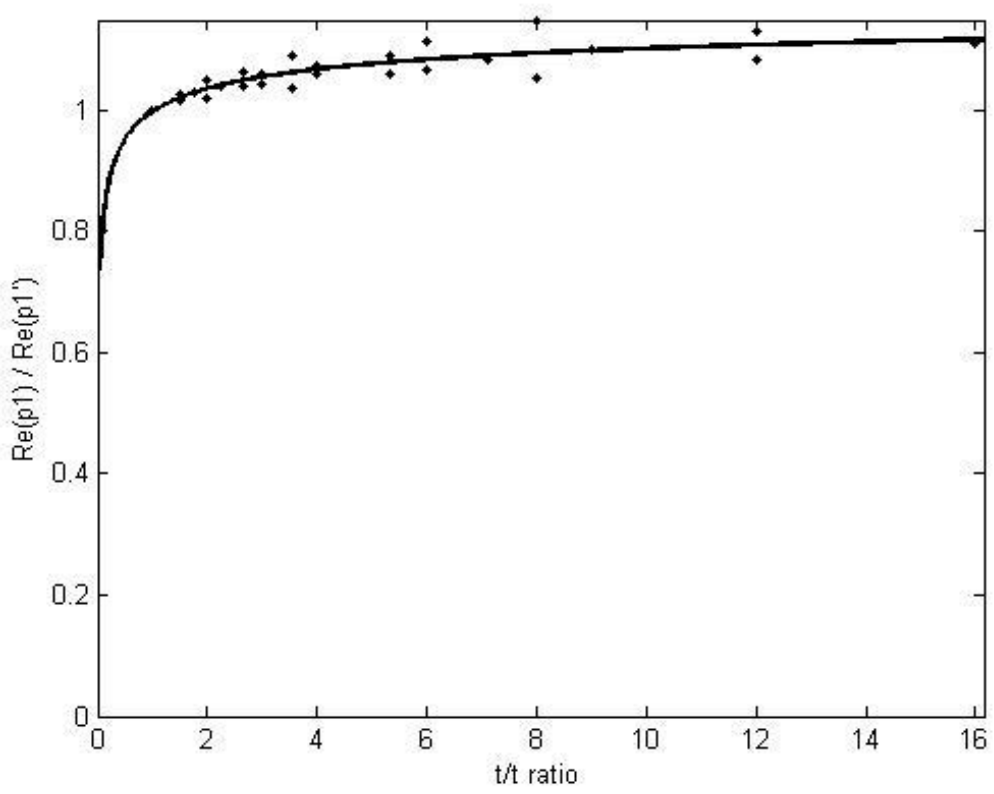

Figure 6. Numerical correlation between $\operatorname{Re}\left(\mathrm{p}_{1}\right) / \operatorname{Re}\left(\mathrm{p}_{1}{ }^{\prime}\right)$ to $\mathrm{t} / \mathrm{t}^{\prime}$ ratio.

From the numerical values of Table 6, the following models emerge through regression analysis for the real and imaginary part of the first of the six roots of the equation under consideration.

$$
\frac{\operatorname{Re}\left(\mathrm{p}_{1}\right)}{\operatorname{Re}\left(\mathrm{p}_{1}{ }^{\prime}\right)}=-0.2351\left(\frac{\mathrm{t}}{\mathrm{t}^{\prime}}\right)^{-0.2546}+1.233, \mathrm{R}^{2}=0.71
$$




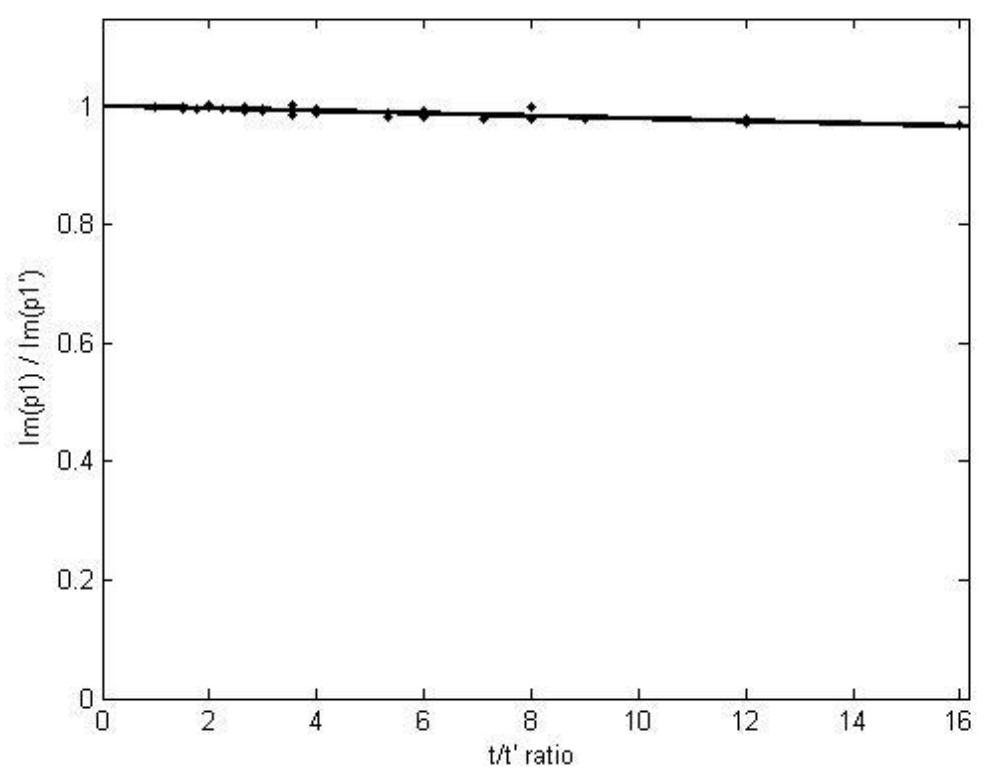

Figure 7. Numerical correlation between $\operatorname{Im}\left(\mathrm{p}_{1}\right) / \operatorname{Im}\left(\mathrm{p}_{1}{ }^{\prime}\right)$ to $\mathrm{t} / \mathrm{t}^{\prime}$ ratio.

$$
\frac{\operatorname{Im}\left(\mathrm{p}_{1}\right)}{\operatorname{Im}\left(\mathrm{p}_{1}{ }^{\prime}\right)}=-0.00214\left(\frac{\mathrm{t}}{\mathrm{t}^{\prime}}\right)+1.002, \mathrm{R}^{2}=0.72
$$

The equation tested is the same as that of example 3.1 except that the step of the interval to which its coefficients belong is $\mathrm{S}=0.5$ instead of $\mathrm{S}=1$. This has led to an increase of $\mathrm{N}$ and $\mathrm{N}_{\mathrm{EQ}}$ with regard to example 3.1. The equation (36) has a correlation coefficient of $\mathrm{c}$ $=0.84$ and equation (37) a correlation coefficient of $\mathrm{c}=0.85$.

\subsection{Approximate root estimation of equation $x^{6}+x^{2}+2 x+2=0$}

Assuming the random polynomial equation $\mathrm{P}(\mathrm{x})=\mathrm{x}^{6}+\mathrm{x}^{2}+2 \mathrm{x}+2=0$, where pq $=0$ and $\{r, s, t\} \in[1,2]$. First it is checked if the constant term of $\mathrm{P}(\mathrm{x})$ complies with equation (13); it is found that it does not apply because $\mathrm{t}^{\prime}=1$, therefore, for the solution of $\mathrm{P}(\mathrm{x})$ the model of examples 3.1 or 3.3 can be applied. It is preferred to apply the same model as in example 3.3 due to the more simplified equations (36) and (37) compared to (32) and (33). The equation is formed:

$$
Q(x)=x^{6}+x^{2}+2 x+1=0
$$

The roots of $\mathrm{Q}(\mathrm{x})$ are the solutions of the depressed cubic equations (39) and (40) and which in turn are calculated from equations (16) - (25).

$$
\begin{aligned}
& x^{3}+1 i x+1 i=0 \\
& x^{3}-1 i x-1 i=0
\end{aligned}
$$

Cubic depressed equations (39) and (40) have the following roots; $\rho_{1}^{\prime}=1.0357+$ $0.7802 \mathrm{i}, \quad \rho_{2}^{\prime}=1.0357-0.7802 \mathrm{i}, \quad \rho_{3}{ }^{\prime}=-0.3454+1.0047 \mathrm{i}, \quad \rho_{4}{ }^{\prime}=-0.3454-1.0047 \mathrm{i}$, $\rho_{5}{ }^{\prime}=-0.6903-0.2245 \mathrm{i}, \rho_{6}{ }^{\prime}=-0.6903+0.2245 \mathrm{i}$. The models of equations (32) - (37) refer only to the first of the six roots of the sextic polynomials examined, hence $\rho_{1}$ and $\rho_{1}{ }^{\prime}$. 
By applying equations (36) and (37) to the real part of the approximate complex root, the following results are obtained:

$$
\begin{gathered}
\frac{\operatorname{Re}\left(\mathrm{p}_{1}\right)}{\operatorname{Re}\left(\mathrm{p}_{1}{ }^{\prime}\right)}=-0.2351\left(\frac{\mathrm{t}}{\mathrm{t}^{\prime}}\right)^{-0.2546}+1.233 \Leftrightarrow \\
\Leftrightarrow \operatorname{Re}\left(\mathrm{p}_{1}\right)=\operatorname{Re}\left(\mathrm{p}_{1}^{\prime}\right)\left[-0.2351\left(\frac{\mathrm{t}}{\mathrm{t}^{\prime}}\right)^{-0.2546}+1.233\right] \Leftrightarrow \\
\Leftrightarrow \operatorname{Re}\left(\mathrm{p}_{1}\right)=1.0357\left[-0.2351\left(\frac{2}{1}\right)^{-0.2546}+1.233\right] \Leftrightarrow \\
\Leftrightarrow \operatorname{Re}\left(\mathrm{p}_{1}\right)=1.0729
\end{gathered}
$$

For the imaginary part of the approximate complex root:

$$
\begin{gathered}
\frac{\operatorname{Im}\left(\mathrm{p}_{1}\right)}{\operatorname{Im}\left(\mathrm{p}_{1}^{\prime}\right)}=-0.00214\left(\frac{\mathrm{t}}{\mathrm{t}^{\prime}}\right)+1.002 \Leftrightarrow \\
\Leftrightarrow \operatorname{Im}\left(\mathrm{p}_{1}\right)=\operatorname{Im}\left(\mathrm{p}_{1}^{\prime}\right)\left[-0.00214\left(\frac{\mathrm{t}}{\mathrm{t}^{\prime}}\right)+1.002\right] \Leftrightarrow \\
\Leftrightarrow \operatorname{Im}\left(\mathrm{p}_{1}\right)=0.7802\left[-0.00214\left(\frac{2}{1}\right)+1.002\right] \Leftrightarrow \\
\Leftrightarrow \operatorname{Im}\left(\mathrm{p}_{1}\right)=0.7784
\end{gathered}
$$

The approximate estimate of the first root $\rho_{1}$ of the random sextic polynomial equation $\mathrm{P}(\mathrm{x})$, is $\rho_{1}=1.0729+0.7784 \mathrm{i}$.

Table 7. The exact roots of $\mathrm{P}(\mathrm{x})$, the roots of $\mathrm{Q}(\mathrm{x})$ and the approximate first root of $\mathrm{P}(\mathrm{x})$

\begin{tabular}{|c|c|c|c|}
\hline & Exact roots of $\mathrm{P}(\mathrm{x})$ & Roots of $\mathrm{Q}(\mathrm{x})$ & Approximate root of $\mathrm{P}(\mathrm{x})$ \\
\hline & $\rho_{1 \mathrm{E}} \ldots \rho_{6 \mathrm{E}}$ & $\rho_{1}{ }^{\prime} \ldots \rho_{6}{ }^{\prime}$ & $\rho_{1}$ \\
\hline 1 & $1.0864+0.7823 \mathrm{i}$ & $1.0357+0.7802 \mathrm{i}$ & $1.0729+0.7784 \mathrm{i}$ \\
\hline 2 & $1.0864-0.7823 \mathrm{i}$ & $1.0357-0.7802 \mathrm{i}$ & - \\
\hline 3 & $-0.2350+1.0659 \mathrm{i}$ & $-0.3454+1.0047 \mathrm{i}$ & - \\
\hline 4 & $-0.2350-1.0659 \mathrm{i}$ & $-0.3454-1.0047 \mathrm{i}$ & - \\
\hline 5 & $-0.8513+0.4603 \mathrm{i}$ & $-0.6903-0.2245 \mathrm{i}$ & - \\
\hline 6 & $-0.8513-0.4603 \mathrm{i}$ & $-0.6903+0.2245 \mathrm{i}$ & - \\
\hline
\end{tabular}

Compared with the exact root $\rho_{1 \mathrm{E}}$ of $\mathrm{P}(\mathrm{x})$ which is $\rho_{1 \mathrm{E}}=1.0864+0.7823 \mathrm{i}$, the following value differences are presented:

$$
\begin{aligned}
& \frac{\operatorname{Re}\left(\rho_{1 \mathrm{E}}\right)-\operatorname{Re}\left(\rho_{1}\right)}{\operatorname{Re}\left(\rho_{1 \mathrm{E}}\right)}=\frac{1.0864-1.0729}{1.0864}=+1.24 \% \\
& \frac{\operatorname{Im}\left(\rho_{1 \mathrm{E}}\right)-\operatorname{Im}\left(\rho_{1}\right)}{\operatorname{Im}\left(\rho_{1 \mathrm{E}}\right)}=\frac{0.7823-0.7784}{0.7823}=+0.5 \%
\end{aligned}
$$

The deviations are small and range within the error $\mathrm{R}^{2}$ of the regression analysis. 


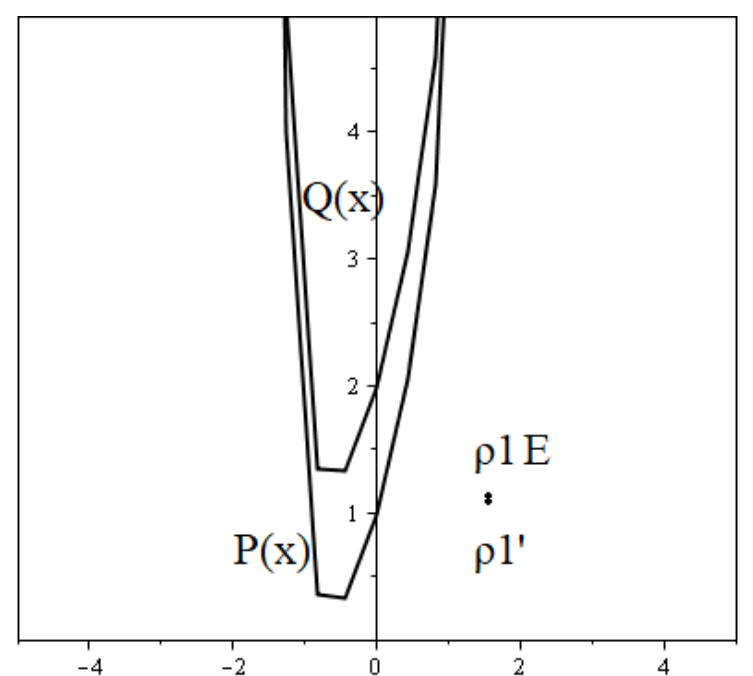

Figure 8 . The curves of the polynomial equations $\mathrm{P}(\mathrm{x})$ and $\mathrm{Q}(\mathrm{x})$ as well as one of the six roots of each polynomial equation $\rho_{1 \mathrm{E}}$ and $\rho_{1}{ }^{\prime}$.

\subsection{Approximate root estimation of equation $x^{6}+1.5 x^{2}+1.2 x+1=0$}

Assuming the random polynomial equation $\mathrm{P}(\mathrm{x})=\mathrm{x}^{6}+1.5 \mathrm{x}^{2}+1.2 \mathrm{x}+1=0$, where $\mathrm{pq}=0$ and $\{\mathrm{r}, \mathrm{s}, \mathrm{t}\} \in[1,2]$. It is found that the constant term $\mathrm{t}^{\prime}=0.24$, therefore, the model of example 3.3 can be used to solve equation $\mathrm{P}(\mathrm{x})$. The equation $\mathrm{Q}(\mathrm{x})$ is formed as follows:

$$
Q(x)=x^{6}+1.5 x^{2}+1.2 x+0.24=0
$$

The roots of $\mathrm{Q}(\mathrm{x})$ are the solutions of the depressed cubic equations (44) and (45).

$$
\begin{aligned}
& x^{3}+1.225 i x+0.49 i=0 \\
& x^{3}-1.225 i x-0.49 i=0
\end{aligned}
$$

The depressed cubic equations (44) and (45) have the following roots; $\rho_{1}^{\prime}=$ $0.9490+0.8037 \mathrm{i}, \quad \rho_{2}^{\prime}=0.9490-0.8037 \mathrm{i}, \quad \rho_{3}{ }^{\prime}=-0.5649+0.8481 \mathrm{i}, \quad \rho_{4}^{\prime}=-0.5649-$ $0.8481 \mathrm{i}, \quad \rho_{5}^{\prime}=-0.3840+0.0444 \mathrm{i}, \quad \rho_{6}{ }^{\prime}=-0.3840+0.0444 \mathrm{i}$. The roots that will be examined in this article are only one of the six; $\rho_{1}$ and $\rho_{1}{ }^{\prime}$. By applying equations (36) and (37) to the real part of the approximate complex root, the following equation arises:

$$
\begin{gathered}
\frac{\operatorname{Re}\left(\mathrm{p}_{1}\right)}{\operatorname{Re}\left(\mathrm{p}_{1}{ }^{\prime}\right)}=-0.2351\left(\frac{\mathrm{t}}{\mathrm{t}^{\prime}}\right)^{-0.2546}+1.233 \Leftrightarrow \\
\Leftrightarrow \operatorname{Re}\left(\mathrm{p}_{1}\right)=\operatorname{Re}\left(\mathrm{p}_{1}^{\prime}\right)\left[-0.2351\left(\frac{\mathrm{t}}{\mathrm{t}^{\prime}}\right)^{-0.2546}+1.233\right] \Leftrightarrow \\
\Leftrightarrow \operatorname{Re}\left(\mathrm{p}_{1}\right)=0.9490\left[-0.2351\left(\frac{0.24}{1}\right)^{-0.2546}+1.233\right] \Leftrightarrow \\
\Leftrightarrow \operatorname{Re}\left(\mathrm{p}_{1}\right)=0.8493
\end{gathered}
$$

For the imaginary part of the approximate complex root:

$$
\frac{\operatorname{Im}\left(\mathrm{p}_{1}\right)}{\operatorname{Im}\left(\mathrm{p}_{1}^{\prime}\right)}=-0.00214\left(\frac{\mathrm{t}}{\mathrm{t}^{\prime}}\right)+1.002 \Leftrightarrow
$$




$$
\begin{gathered}
\Leftrightarrow \operatorname{Im}\left(\mathrm{p}_{1}\right)=\operatorname{Im}\left(\mathrm{p}_{1}{ }^{\prime}\right)\left[-0.00214\left(\frac{\mathrm{t}}{\mathrm{t}^{\prime}}\right)+1.002\right] \Leftrightarrow \\
\Leftrightarrow \operatorname{Im}\left(\mathrm{p}_{1}\right)=0.8037\left[-0.00214\left(\frac{0.24}{1}\right)+1.002\right] \Leftrightarrow \\
\Leftrightarrow \operatorname{Im}\left(\mathrm{p}_{1}\right)=0.8049
\end{gathered}
$$

The approximate estimate of the first root $\rho_{1}$ of the random sextic polynomial equation $\mathrm{P}(\mathrm{x})$, is $\rho_{1}=0.8493+0.8049 \mathrm{i}$.

Table 8. The exact roots of $\mathrm{P}(\mathrm{x})$, the roots of $\mathrm{Q}(\mathrm{x})$ and the approximate first root of $\mathrm{P}(\mathrm{x})$

\begin{tabular}{|c|c|c|c|}
\hline & Exact roots of $\mathrm{P}(\mathrm{x})$ & Roots of $\mathrm{Q}(\mathrm{x})$ & Approximate root of $\mathrm{P}(\mathrm{x})$ \\
\hline & $\rho_{1 \mathrm{E}} \ldots \rho_{6 \mathrm{E}}$ & $\rho_{1}{ }^{\prime} \ldots \rho_{6}{ }^{\prime}$ & $\rho_{1}$ \\
\hline 1 & $1.0004+0.7927 \mathrm{i}$ & $0.9490+0.8037 \mathrm{i}$ & $0.8493+0.8049 \mathrm{i}$ \\
\hline 2 & $1.0004-0.7927 \mathrm{i}$ & $0.9490-0.8037 \mathrm{i}$ & - \\
\hline 3 & $-0.7272+0.5997 \mathrm{i}$ & $-0.5649+0.8481 \mathrm{i}$ & - \\
\hline 4 & $-0.7272-0.5997 \mathrm{i}$ & $-0.5649-0.8481 \mathrm{i}$ & - \\
\hline 5 & $-0.2733+0.7850 \mathrm{i}$ & $-0.3840+0.0444 \mathrm{i}$ & - \\
\hline 6 & $-0.2733-0.7850 \mathrm{i}$ & $-0.3840-0.0444 \mathrm{i}$ & - \\
\hline
\end{tabular}

Compared with the exact root $\rho_{1 \mathrm{E}}$ of $\mathrm{P}(\mathrm{x})$ which is $\rho_{1 \mathrm{E}}=1.0004+0.7927 \mathrm{i}$, the following value differences are presented:

$$
\begin{aligned}
& \frac{\operatorname{Re}\left(\rho_{1 \mathrm{E}}\right)-\operatorname{Re}\left(\rho_{1}\right)}{\operatorname{Re}\left(\rho_{1 \mathrm{E}}\right)}=\frac{1.0004-0.8493}{1.0004}=+15.1 \% \\
& \frac{\operatorname{Im}\left(\rho_{1 \mathrm{E}}\right)-\operatorname{Im}\left(\rho_{1}\right)}{\operatorname{Im}\left(\rho_{1 \mathrm{E}}\right)}=\frac{0.7927-0.8049}{0.7927}=-1.54 \%
\end{aligned}
$$

The deviations are small and range within the error $\mathrm{R}^{2}$ of the regression analysis.

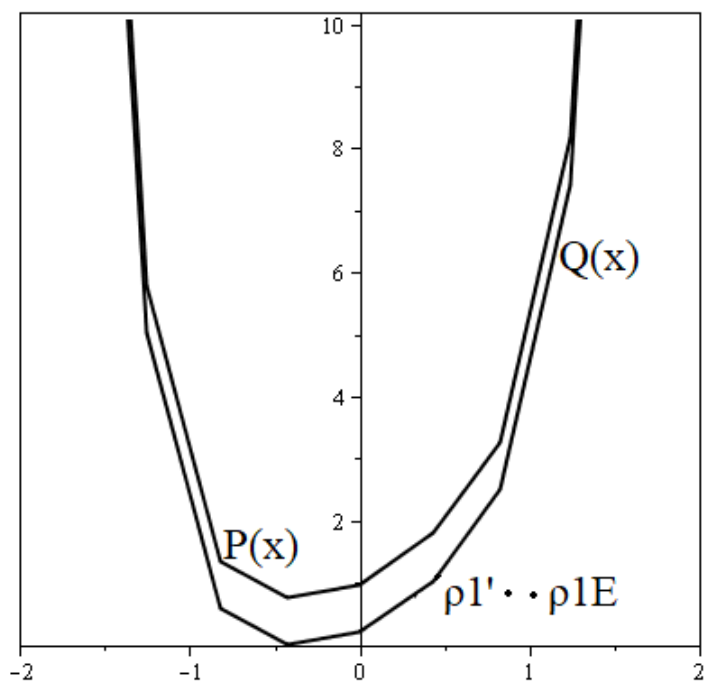

Figure 9. The curves of the polynomial equations $P(x)$ and $Q(x)$ as well as first of the six roots of each polynomial equation $\rho_{1 \mathrm{E}}$ and $\rho_{1}{ }^{\prime}$. 
Flow chart of methodological procedure in units 2.1, 2.2 and 3

\section{Unit 2.1}

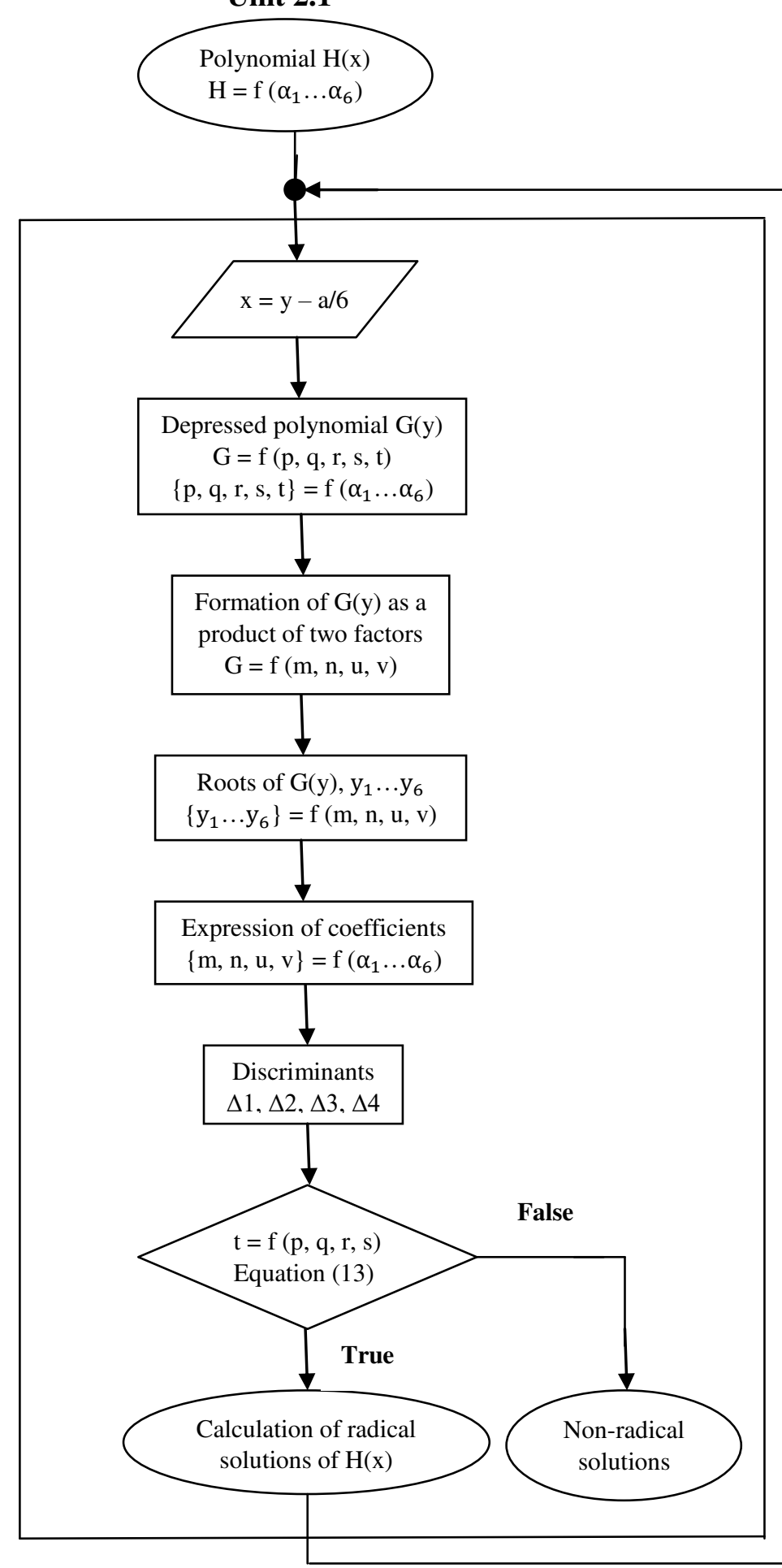

Unit 2.2

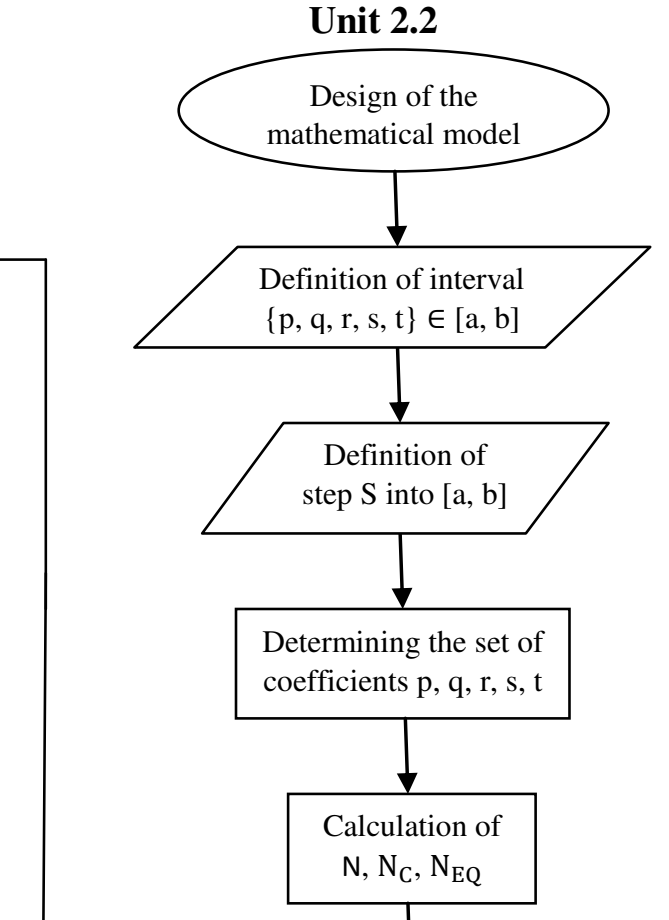

Figure 1 process 


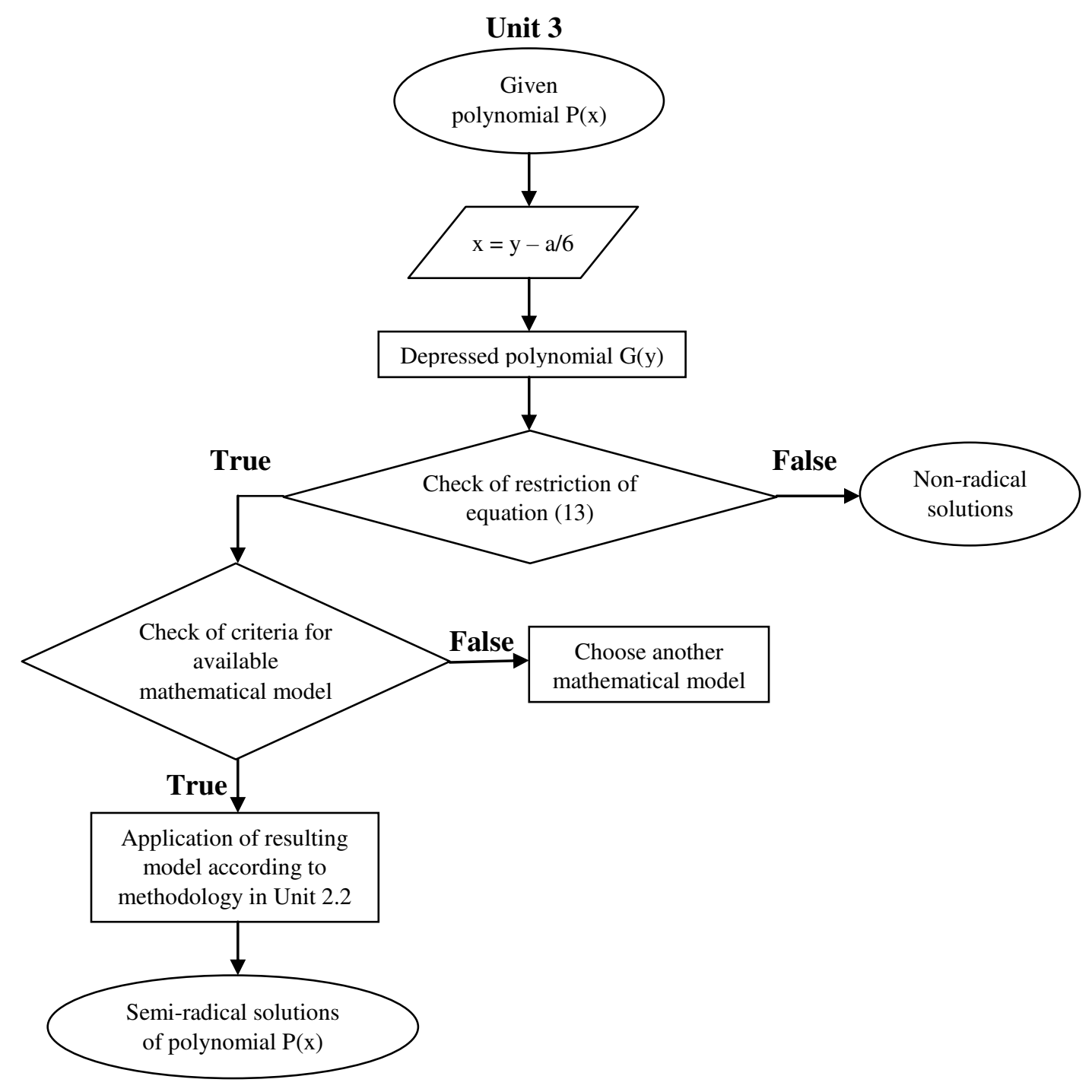

\section{The case of equation $x^{6}+\alpha_{1} x^{5}+\alpha_{2}$}

This equation can be transformed to a depressed sextic polynomial equation without a quintic term, such as (6); therefore, the same methodology applied to equation (6) can be applied in this case to estimate the approximate roots. If $x^{6}+\alpha_{1} x^{5}+\alpha_{2}$, where reducing transformation $\mathrm{x}=\mathrm{y}-\alpha_{1} / 6$, then the equation is transformed as:

$$
y^{6}+p y^{4}+q y^{3}+r y^{2}+s y+t=0
$$

Where $\{p, q, r, s, t\}=f\left(\alpha_{1}, \alpha_{2}\right)$ and the following coefficients:

$\mathrm{p}=-\frac{5 \alpha_{1}^{2}}{12}+\alpha_{2}$

$\mathrm{q}=\frac{5 \alpha_{1}^{3}}{27}-\frac{2 \alpha_{1} \alpha_{2}}{3}$

$r=-\frac{5 \alpha_{1}^{4}}{144}+\frac{\alpha_{1}^{2} \alpha_{2}}{6}$ 
$\mathrm{s}=\frac{\alpha_{1}^{5}}{324}-\frac{\alpha_{1}^{3} \alpha_{2}}{54}$

$\mathrm{t}=-\frac{5 \alpha_{1}^{6}}{46656}+\frac{\alpha_{1}^{4} \alpha_{2}}{1296}$

\subsection{The case of equation $x^{6}+\alpha_{1} x+\alpha_{2}$}

This sextic equation is similar to the quintic equation of the Bring - Jerrard form, it is a special case as it is not possible to algebraically estimate the roots of the corresponding defined equation $\mathrm{Q}(\mathrm{x})$ according to (16) - (25) due to the constraint $\mathrm{p}^{2}-4 \mathrm{r} \neq 0$, whereas equation (13) cannot be applied, since no fixed term $t^{\prime}$ is defined.

\subsection{Finding a general sextic polynomial equation so that it is solved by radicals, with a fixed term $\alpha_{6}=f\left(\alpha_{1} \ldots \alpha_{5}\right)$ and $\left\{\alpha_{1} \ldots \alpha_{5}\right\} \in C$}

In the last application of this article, the methodology of finding the coefficients of a general sextic polynomial equation follows so that it is possible to calculate the radicals of the equation according to formulas (6) to (25). The equation must have a fixed term defined according to equation (13) Assuming the equation:

$$
P(x)=x^{6}+\alpha_{1} x^{5}+\alpha_{2} x^{4}+\alpha_{3} x^{3}+\alpha_{4} x^{2}+\alpha_{5} x+\alpha_{6}=0
$$

In order for (50) to be solved by radicals, the following relation between the initial coefficients $\alpha_{1} \ldots \alpha_{5}$ and the fixed term $\alpha_{6}$ must be valid; the relation follows from (13) solving with respect to $\alpha_{6}$. The equation (51) becomes complex if the coefficients p, q, r, s, t are replaced with respect to $\alpha_{1} \ldots \alpha_{6}$.

$$
\begin{gathered}
\alpha_{6}=\frac{5 \alpha_{1}^{6}}{46656}-\frac{\alpha_{1}^{4} \alpha_{2}}{1296}+\frac{\alpha_{1}^{3} \alpha_{3}}{216}-\frac{\alpha_{1}^{2} \alpha_{4}}{36}-\frac{\alpha_{1} \alpha_{5}}{6}+\left(\frac{5 \alpha_{1}^{3}}{54}-\frac{\alpha_{1} \alpha_{2}}{3}+\frac{\alpha_{3}}{2}\right)^{2}- \\
-\frac{\left(\left(-\frac{5 \alpha_{1}^{2}}{12}+\alpha_{2}\right)\left(\frac{5 \alpha_{1}^{3}}{27}-\frac{2 \alpha_{1} \alpha_{2}}{3}+\alpha_{3}\right)-\frac{\alpha_{1}^{5}}{162}+\frac{\alpha_{1}^{3} \alpha_{2}}{27}-\frac{\alpha_{1}^{2} \alpha_{3}}{6}+\frac{2 \alpha_{1} \alpha_{4}}{3}\right)^{2}}{\left(-\frac{5 \alpha_{1}^{2}}{6}+2 \alpha_{2}\right)^{2}+\frac{5 \alpha_{1}^{4}}{9}-\frac{8 \alpha_{1}^{2} \alpha_{2}}{3}+8 \alpha_{1} \alpha_{3}-16 \alpha_{4}}
\end{gathered}
$$

Below is the finding of the radicals for a depressed form of a sextic equation with a definite fixed term, so that it can be solved by radicals. The following equation arises:

$$
x^{6}+6 x^{4}+4 x^{3}+6 x^{2}+6 x+1=0
$$

The control of the fixed term displays the compliance with equation (13), and the discriminants of equation (52) are:

$$
\mathrm{m}=\mathrm{u}=\frac{\mathrm{p}}{2} \pm \sqrt{\frac{\mathrm{p}^{2}}{4}-\mathrm{r}}=\frac{6}{2} \pm \sqrt{\frac{36}{4}-6}=3 \pm \sqrt{3}
$$




$$
\begin{gathered}
\mathrm{n}=\mathrm{v}=\frac{\mathrm{q}}{2} \pm \sqrt{\frac{\mathrm{q}^{2}}{4}-\mathrm{t}}=\frac{4}{2} \pm \sqrt{\frac{16}{4}-1}=2 \pm \sqrt{3} \\
\Delta_{1}=\Delta_{2}=3 \\
\Delta_{3}=\left(1+\frac{\sqrt{3}}{2}\right)^{2}+\left(1+\frac{\sqrt{3}}{3}\right)^{3} \\
\Delta_{4}=\left(1-\frac{\sqrt{3}}{2}\right)^{2}+\left(1-\frac{\sqrt{3}}{3}\right)^{3}
\end{gathered}
$$

The radicals of equation (52) are the following:

$$
\begin{aligned}
& \rho_{1}=\sqrt[3]{-1-\frac{\sqrt{3}}{2}+\sqrt{\left(1+\frac{\sqrt{3}}{2}\right)^{2}+\left(1+\frac{\sqrt{3}}{3}\right)^{3}}}+\sqrt[3]{-1-\frac{\sqrt{3}}{2}-\sqrt{\left(1+\frac{\sqrt{3}}{2}\right)^{2}+\left(1+\frac{\sqrt{3}}{3}\right)^{3}}} \\
& \rho_{2}=\omega_{1} \sqrt[3]{-1-\frac{\sqrt{3}}{2}+\sqrt{\left(1+\frac{\sqrt{3}}{2}\right)^{2}+\left(1+\frac{\sqrt{3}}{3}\right)^{3}}}+\omega_{2} \sqrt[3]{-1-\frac{\sqrt{3}}{2}-\sqrt{\left(1+\frac{\sqrt{3}}{2}\right)^{2}+\left(1+\frac{\sqrt{3}}{3}\right)^{3}}} \\
& \rho_{3}=\omega_{2} \sqrt[3]{-1-\frac{\sqrt{3}}{2}+\sqrt{\left(1+\frac{\sqrt{3}}{2}\right)^{2}+\left(1+\frac{\sqrt{3}}{3}\right)^{3}}}+\omega_{1} \sqrt[3]{-1-\frac{\sqrt{3}}{2}-\sqrt{\left(1+\frac{\sqrt{3}}{2}\right)^{2}+\left(1+\frac{\sqrt{3}}{3}\right)^{3}}} \\
& \rho_{4}=\sqrt[3]{-1+\frac{\sqrt{3}}{2}+\sqrt{\left(1-\frac{\sqrt{3}}{2}\right)^{2}+\left(1-\frac{\sqrt{3}}{3}\right)^{3}}}+\sqrt[3]{-1+\frac{\sqrt{3}}{2}-\sqrt{\left(1-\frac{\sqrt{3}}{2}\right)^{2}+\left(1-\frac{\sqrt{3}}{3}\right)^{3}}} \\
& \rho_{5}=\omega_{1} \sqrt[3]{-1+\frac{\sqrt{3}}{2}+\sqrt{\left(1-\frac{\sqrt{3}}{2}\right)^{2}+\left(1-\frac{\sqrt{3}}{3}\right)^{3}}}+\omega_{2} \sqrt[3]{-1+\frac{\sqrt{3}}{2}-\sqrt{\left(1-\frac{\sqrt{3}}{2}\right)^{2}+\left(1-\frac{\sqrt{3}}{3}\right)^{3}}} \\
& \rho_{6}=\omega_{2} \sqrt[3]{-1+\frac{\sqrt{3}}{2}+\sqrt{\left(1-\frac{\sqrt{3}}{2}\right)^{2}+\left(1-\frac{\sqrt{3}}{3}\right)^{3}}}+\omega_{1} \sqrt[3]{-1+\frac{\sqrt{3}}{2}-\sqrt{\left(1-\frac{\sqrt{3}}{2}\right)^{2}+\left(1-\frac{\sqrt{3}}{3}\right)^{3}}}
\end{aligned}
$$




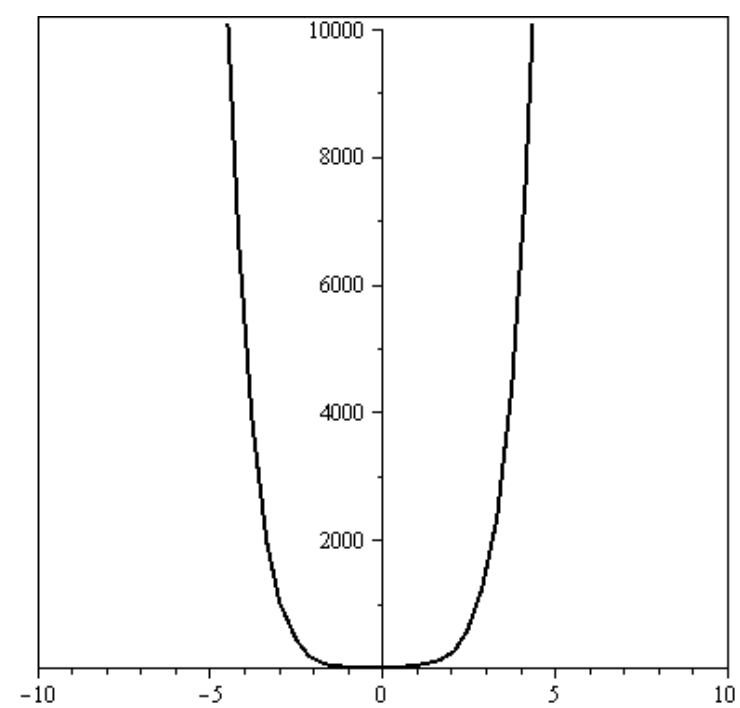

Figure 10. The curve of the depressed sextic equation (56).

\section{Discussion}

In this article, an effort was made to explain and present as much as possible, a complex methodology that leads to the estimation of the roots of the general sextic polynomial equation as well as various other depressed forms of sextic equations. The methodology is complex as the first part includes algebraic procedures and the second part includes a quantitative method for formulating the mathematical model for estimating the roots of the examined sextic polynomial equation under the insertion of an error. The choice of the mathematical model is made so that there is the maximum correlation coefficient; the minimum possible error between the estimated root and the exact root of the equation. The reliability of the proposed mathematical models depends on the number of numerical values to be taken into account in the sample. The value range of the coefficients for which a polynomial equation will be investigated and the step are determined by the researcher. The article presents the application of the methodology in practice with five different applications; in three of them mathematical models are derived for estimating roots of polynomial equations within a certain interval and step of values. In the other two applications the estimation of the roots of some equations is performed based on the above-mentioned three models; any discrepancies and errors between the real and complex part of one of the six roots for each polynomial equation are also examined.

The volume of data obtained for the investigation of polynomial equations of bigger interval and step values with respect to the coefficients $\mathrm{p}, \mathrm{q}, \mathrm{r}, \mathrm{s}$, t, is such that it cannot be applied and examined in this article, therefore, we suffice to quote applications and examples 3.1 to 3.5. It can be deduced that the solutions that result for the sixth-degree polynomials from the specific methodology are "semi-radical" solutions.

\section{Conclusions}

The methodology presented and applied in this article leads to the derivation of mathematical models which can identify (with some error) the approximate roots of a given general sextic polynomial equation $\mathrm{P}(\mathrm{x})$ as well as other depressed forms of sextic polynomial equations that cannot be solved by radicals. The error of the approximate roots of the polynomial equation depends on the derived mathematical model based on the methodology described. The resulting mathematical model for each tested equation is determined by the volume of numerical data in the sample to be collected, the number of values depends on the number of 
coefficients of the tested equation, the interval of values to be taken into account for the coefficients as well as the step that is valid within the interval. From the application of the complex methodology presented, it can be deduced that for any given general sextic polynomial equation $\mathrm{P}$ with coefficients within the interval $[\mathrm{a}, \mathrm{b}]$ as well as for some other forms of sextic polynomials that cannot be solved by radicals, a definite equation $\mathrm{Q}(\mathrm{x})$ corresponds which has equal coefficients with $\mathrm{P}(\mathrm{x})$ except for its constant term which is different and depends on the other coefficients of $Q(x)$ so that $Q(x)$ is solved by radicals. If a group of pairs of equations $\mathrm{P}(\mathrm{x})$ and $\mathrm{Q}(\mathrm{x})$ is formed with coefficients within [a, b], then from the numerical correlation of the roots of $\mathrm{P}(\mathrm{x})$, the radicals of $\mathrm{Q}(\mathrm{x})$ and the constant terms of $\mathrm{P}(\mathrm{x}), \mathrm{Q}(\mathrm{x})$, a mathematical model of approximate estimation of the roots of a given equation $\mathrm{P}(\mathrm{x})$ within $[\mathrm{a}, \mathrm{b}]$ can be obtained; where the approximate roots include both the initial coefficients of $\mathrm{P}(\mathrm{x})$ and the numerical correlation derived from the regression analysis.

\section{Declaration}

\section{The author declares that there is no conflict of interest.}

\section{References}

1. Ruffini, P. (1799). Teoria Generale delle Equazioni, in cui si dimostra impossibile la soluzione algebraica delle equazioni generali di grado superiore al quarto [General Theory of equations, in which the algebraic solution of general equations of degree higher than four is proven impossible]. Book on Demand Ltd. ISBN: 978-5519056762

2. Abel, N. H. (1881). Mémoire sur les équations algébriques, ou l'on démontre l'impossibilité de la résolution de l'équation générale du cinquième degré. In $\mathrm{S}$. Ludwig, L. Sophus (Ed.). Euvres Complètes de Niels Henrik Abel, I (2nd ed.), (pp. 28-33), Grondahl \& Son.

3. Abel, N. H. (1881). Démonstration de l'impossibilité de la résolution algébrique des équations générales qui passent le quatrième degré. In S. Ludwig, L. Sophus (Ed.). Euvres Complètes de Niels Henrik Abel, I (2nd ed.), (pp. 66-87), Grondahl \& Son.

4. Tignol, J. P. (2001). Galois' Theory of Algebraic Equations. World Scientific, Louvain, Belgium. DOI: 10.1142/4628

5. Stewart, I. N. (2015). Galois Theory (4th ed.), CRC Press. ISBN 978-1-4822-4582-0

6. Kouropoulos, G. P. (2016). Prosdiorismos rizikon se ektovathmies polyonimikes eksisoseis ypo proypotheseis [Determination of roots of sextic polynomial equations under conditions], Easywriter, Athens. ISBN: 978-960-93-7762-1

7. Brown, S. C., Spearman, B. K., Yang, Q. (2013). On sextic trinomials with Galois group C-6, S-3 OR C-3 x S-3. Journal of Algebra and Its Applications, 12(1), 1-9. DOI: $10.1142 / \mathrm{S} 0219498812501289$

8. Cavallo, A. (2019). Galois groups of symmetric sextic trinomials. arXiv:1902.00965v1 [math.GR]. https://arxiv.org/abs/1902.00965

9. Awtrey, C. and Jakes, P. (2020). Galois Groups of Even Sextics Polynomials, Canadian Mathematical Bulletin, 63(1), 670-676. DOI: 10.4153/50008439519000754

10. Dickson, L. E. (1925). Resolvent sextics of quintic equations. Bulletin of American Mathematical Society, 31(9-10), 515-523. https://www.ams.org/journals/bull/1925-3109/S0002-9904-1925-04097-5/

11. Girstmair, K. (1983). On the computation of resolvents and Galois groups. Manuscripta Mathematica, 43, 289-307. DOI: 10.1007/BF01165834

12. Hurley, A. C., Head, A. K. (1987). Explicit Galois resolvents for sextic equations. Quantum Chemistry, 31(2), 345-359. DOI: 10.1002/qua.560310306

13. Awtrey, C., French, R., Jakes, P., Russell, A. (2015). Irreducible sextic polynomials and 
theirabsolute resolvents. The Minnesota Journal of Undergraduate Mathematics, 1(1), $1-18$.

14. Harrington, J., Jones, L. (2017). The irreducibility of power compositional sextic polynomials and their Galois groups. MATHEMATICA SCANDINAVICA, 120(2), 181-184. DOI: 10.7146/math.scand.a-25850

15. Hagedorn, T. R. (2000). General Formulas for Solving Solvable Sextic Equations. Journal of Algebra, 233(2), 704-757. DOI: 10.1006/jabr.2000.8428

16. Boswell, C., Glasser, M. L. (2005). Solvable Sextic Equations. arXiv:math-ph/0504001 [math.ph]. https://arxiv.org/pdf/math-ph/0504001.pdf

17. Coble, A. B. (1911a). The Reduction of the sextic equation to the Valentiner FormProblem. Mathematische Annalen, 70, 337-350. https://eudml.org/doc/158500

18. Valentiner, H. (1889). De endelige Transformations-gruppers Theori, Videnkabernes Selskabs Skrifter (in Danish), Bianco Lunos, 6.

19. Coble, A. B. (1911b). An application of Moore's cross-ratio group to the solution of the sextic equation. Transactions for the American Mathematical Society, 12(3), 311-325. DOI: $10.2307 / 1988669$

20. Moore, E. H. (1900). The Cross-Ratio Group of $n$ ! Cremona Transformations of Order n-3 in Flat Space of n-3 Dimensions. American Journal of Mathematics, 22(3), 279291. DOI: $10.2307 / 2369857$

21. Cole, F. N. (1886). A Contribution to the Theory of the General Equation of the Sixth Degree, American Journal of Mathematics, 8(3), 265-286. DOI: 10.2307/2369410

22. Weisstein, E. W. Sextic Equation. From MathWorld - A Wolfram Web Resource. https://mathworld.wolfram.com/SexticEquation.html

23. Mochimaru, Y. (2005). Solution of Sextic Equations. International Journal of Pure and Applied Mathematics, 23(4), 575-583. https://ijpam.eu/contents/2005-23-4/9/9.pdf

24. Kulkarni, R. G. (2008). Solving Sextic Equations. Journal of Mathematics, Atlantic Electronic, 3(1), 56-60. http://euclid.trentu.ca/aejm/V3N1/Kulkarni.V3N1.pdf

25. Crass, S. (1999). Solving the Sextic by Iteration: A Study in Complex Geometry and Dynamics. Experimental Mathematics, 8(3), 209-240. DOI: 10.1080/10586458.1999.10504401

26. Doyle, P., McMullen, C. (1989). Solving the quintic by iteration, 163, 151-180. DOI: 10.1007/BF02392735 


\section{Supplementary Files}

This is a list of supplementary files associated with this preprint. Click to download.

- Polynomial1testregression.xlsx 